\title{
Current Challenges in the Management of Chronic Pelvic Pain in Women: From Bench to Bedside
}

\author{
Vânia Meira Siqueira-Campos $\mathbb{D}^{\prime}$, Mariana Siqueira Campos de Deus $\mathbb{D}^{1}$, Omero Benedicto Poli-Neto $\mathbb{D}^{2,3}$, \\ Julio Cesar Rosa-e-Silva $\mathbb{D}^{3}$, José Miguel de Deus $\mathbb{D}^{\prime}$, Délio Marques Conde $\mathbb{D}^{\prime}$ \\ 'Department of Obstetrics and Gynecology, School of Medicine, Federal University of Goiás, Goiânia, Goiás, Brazil; ${ }^{2}$ Laboratory for Translational \\ Data Science, Ribeirão Preto Medical School, University of São Paulo, Ribeirão Preto, São Paulo, Brazil; ${ }^{3}$ Department of Obstetrics and Gynecology, \\ Ribeirão Preto Medical School, University of São Paulo, Ribeirão Preto, São Paulo, Brazil \\ Correspondence: Délio Marques Conde, Department of Obstetrics and Gynecology, School of Medicine, Federal University of Goiás, Rua 235 S/N, \\ Setor Leste Universitário, Goiânia, 74605-050, Goiás, Brazil, Tel +55 623209615 I, Email delioconde@gmail.com
}

\begin{abstract}
Chronic pelvic pain (CPP) affects a significant proportion of women worldwide And has a negative impact on several aspects of these women's lives including mental health, work, relationships and sexual function, among others. This set of factors ultimately reflects negatively on quality Of life. The physiopathology of CPP is complex and remains to be fully clarified; however, recent advances have increased understanding of the mechanisms involved in chronic pain in general, and more specifically, CPP. Nonetheless, even when a detailed clinical history is obtained, meticulous physical examination is performed and imaging resources are appropriately used, the organic cause of the pain may still fail to be identified in a substantial number of women with CPP. Management of CPP may therefore be challenging. This narrative review was aimed at adding to the available literature on the subject, presenting and discussing the principal characteristics of CPP in women. The paper highlights gaps in the literature while providing the most up-to-date evidence associated with the physiopathology and classification of pain, its diagnosis and treatment. In addition, current challenges in the management of women with CPP are discussed.
\end{abstract}

Keywords: central sensitization, chronic pain, neuropathic pain, nociplastic pain, pain neuroscience education

\section{Introduction}

Chronic pelvic pain (CPP) is a common condition that can affect women at any time during their adult lives. Although more frequent during the reproductive years, it may originate in or extend beyond the menopause. CPP may be the result of an underlying condition that has developed, or it could be associated with different conditions or even with other clinical complaints such as sexual dysfunction, mood swings, abnormal uterine bleeding or urinary and bowel complaints, among others. CPP affects a significant proportion of women and exerts a negative impact on their life course, being frequently associated with a reduced quality of life, symptoms of anxiety and depression, reduced work capacity and a decrease in sexual satisfaction. ${ }^{1,2}$ In addition, CPP in women is associated with high direct and indirect medical costs, estimated at 4.9 billion dollars annually in the USA, ${ }^{3,4}$ and with reduced productivity in women. ${ }^{3}$ Therefore, in addition to representing a problem relevant to the patient herself, CPP also appears to represent an economic burden on the healthcare system worldwide. ${ }^{5,6}$ Although symptoms can be treated and sometimes suppressed, recurrence is common, leading to frustration, both for patients and for healthcare professionals. Adequate clinical characterization and greater understanding of the physiopathological events involved will result in advances towards more effective treatment, particularly over the long term.

The relevance of this subject prompted us to conduct this narrative review in which the principal aspects of CPP in women are presented and discussed. Gaps in knowledge are highlighted, and the most up-to-date evidence in the literature is presented. In addition, the paper discusses current challenges in the treatment of women with CPP. 


\section{Search Methods}

A search was conducted of the Medline, Embase and SciELO (Scientific Electronic Library Online) databases up to the cut-off date of October 15, 2021, using the terms chronic pelvic pain, central sensitization, hyperalgesia, chronic pain, neuromodulation, women, somatic pain, visceral pain, nociplastic pain and neuropathic pain.

Original articles, systematic reviews, meta-analyses and consensus reports from medical societies, published in English, were evaluated. Article references were also scrutinized to identify those most relevant and most closely associated with the subject matter. All the articles retrieved were meticulously examined before being included in the present narrative review.

\section{Definition}

There are various definitions of CPP in the literature, with differences sometimes being subtle and at other times less so. The American College of Obstetricians and Gynecologists (ACOG) defines CPP as

pain symptoms perceived to originate from pelvic organs/structures typically lasting more than 6 months. It is often associated with negative cognitive, behavioral, sexual and emotional consequences as well as with symptoms suggestive of lower urinary tract, sexual, bowel, pelvic floor, myofascial, or gynecological dysfunction.

Cyclic pelvic pain is also considered a form of CPP if there are significant cognitive, behavioral, sexual and emotional consequences involved. Pain triggered by coitus is a controversial issue, but one that has been discussed as a component symptom of CPP. ${ }^{7,8}$

CPP may or may not be associated with other medical conditions. When an association is established, it is reasonable to hypothesize that the pain is due to some physiopathological mechanism of the underlying disease such as inflammation, vascular or mechanical alterations. However, CPP may sometimes be completely dissociated from any other medical condition or may persist even after the woman has undergone adequate treatment for the underlying disease. Consequently, distinguishing between states of chronic secondary pain and states of chronic primary pain, as proposed by the International Association for the Study of Pain (IASP), also seems to be important. ${ }^{9}{ }^{10}$ Although CPP can also occur in men, that aspect is not within the scope of this review.

\section{Prevalence}

The prevalence of CPP worldwide ranges from $2 \%$ to $27 \%$, with rates of around $4 \%$ in developed countries. ${ }^{11,12}$ Gynecological and non-gynecological conditions frequently overlap in up to $60 \%$ of cases of CPP. ${ }^{8}$ On the other hand, in approximately one-third of patients, no pelvic disease is identified. ${ }^{13}$ Around $60-80 \%$ of patients present with complaints that fulfill the International Classification of Diseases, 10th revision (ICD-10) criteria for somatoform disorder. ${ }^{14}$ Indeed, the condition is responsible for $10-20 \%$ of gynecological visits, $20 \%$ of hysterectomies and $40 \%$ of gynecological laparoscopies. ${ }^{3}$ Even after an etiological diagnosis has been reached, when that is possible, and appropriate treatment has been given, symptoms may recur in over a third of cases. ${ }^{15}$

\section{Etiology}

CPP is a multifactorial condition for which differential diagnosis requires a thorough panel work-up. ${ }^{8}$ The most appropriate approach may be to establish an adequate association between the clinical symptoms and the possible physiopathological mechanisms involved, as shown in Figure 1. In addition to providing an idea with respect to the systems that are affected, this approach facilitates the implementation of more effective measures to control the pain or flare-ups.

\section{Physiopathology}

Since this is a condition that can have numerous primary causes and can be associated with many other disturbances, the physiopathology of the disease is complex and remains to be completely clarified. Discussing the specific 


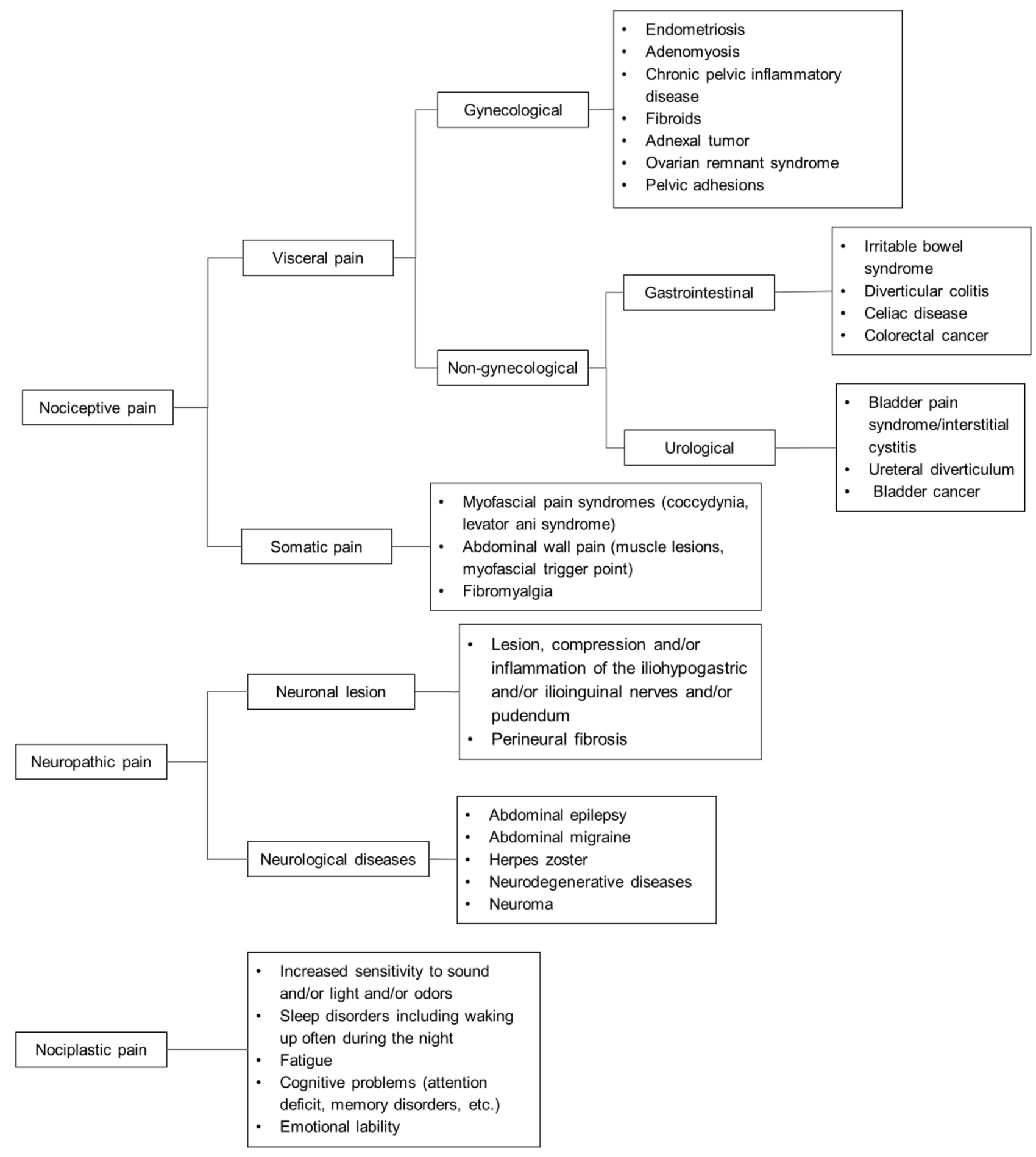

Figure I Classification of the mechanisms of pain and the causes of chronic pelvic pain in women.

Notes: Psychosocial factors such as adverse childhood events (physical, sexual, emotional abuse), physical and/or sexual abuse in adult life, depressive disorders, anxiety disorders, pain catastrophizing and other mental disorders can be associated with chronic pelvic pain in women. The nervous system, endocrine system and immune system are involved in the different types of chronic pelvic pain.

physiopathology associated with each cause would result in this review being excessively long and of very little clinical use. Nevertheless, some points should be highlighted.

Nociception is normally an important process in detecting a potentially harmful stimulus. In physiological circumstances, nociception is protective and useful in preventing lesions, either by inducing a nociceptive withdrawal reflex or 
by promoting an unpleasant feeling that leads to complex emotional and behavioral strategies resulting in the avoidance of that stimulus. Finally, pain, in general, is a phenomenon that is to a certain extent "normal" and "desirable". ${ }^{16}$ To this end, the body uses specialized peripheral and central sensory neurons (nociceptors) capable of encoding noxious stimuli; ${ }^{17,18}$ however, poorly adapted changes to these physiological mechanisms can result in chronic pain. ${ }^{17}$

Therefore, nociceptive pain is pain that "arises from actual or threatened damage to non-neural tissue and is due to the activation of nociceptors". ${ }^{18}$ Nociceptive pain can be visceral or somatic depending on the origin of the nociceptive stimulus and may involve different transmission pathways, entailing different clinical characteristics. Visceral forms of pain are the result of afferent stimuli that travel through the nociceptors located in the visceral walls and reach the spinal cord through afferent nerve fibers, predominantly C-nerve fibers, which is why their location is characteristically imprecise. In the majority of cases, they are triggered through a process of distension, inflammation or by increased contractility of the structure. ${ }^{19}$ Somatic pain originates in the fascia, muscles, tendons and other structures that are not specifically nervous structures. Although somatic pain also arises from peripheral nerve terminals, similar to visceral nociceptors, afference is achieved predominantly through A-delta fibers, giving this form of pain the characteristic of being "more precisely located". The triggers are normally the same as those involved in pain of visceral origin, with direct trauma and chronic inflammatory processes being the most common. ${ }^{20,21}$

Neuropathic pain results from demonstrable neurological damage "or a disease that satisfies established neurological diagnostic criteria." It may be central or peripheral depending on the site of the somatosensory nervous system affected. ${ }^{18}$ This type of pain is associated with deregulated mechanisms of neuronal excitability and is triggered by an inflammatory or compressive process applied directly onto the neuronal fiber. As these neuronal fibers are clustered and carry different stimuli in addition to the nociceptive stimuli, other symptoms such as hypoesthesia, dysesthesia, paresthesia or even anesthesia are often present in the corresponding dermatome. ${ }^{22}$

Under certain circumstances, when the stimulus is persistent or intense enough, the nociceptive system becomes sensitized, as characterized by a reduction in the threshold at which the nociceptor is activated and in which the response to subsequent inputs may be amplified. This sensitization is usually also protective and, although it can last for a considerable time, the phenomenon is reversible, not permanent, and the pain thresholds return to baseline values after a period of time without the painful stimulus. A process of peripheral sensitization characterizes this potentially temporary situation, the maintenance of which requires the presence of an ongoing sustained disorder or peripheral stimulus. ${ }^{23}$ Each disease involves its own mechanism or set of mechanisms that lead to these alterations. These mechanisms may be repeated in different conditions, since there are abnormalities that are common to women with CPP such as, for example, an increase in the number of nerve fibers in the endometrium irrespective of whether the woman has endometriosis, adenomyosis and/or uterine fibroids. ${ }^{24}$

Furthermore, some clinical syndromes such as CPP involve perception of persistent pain, often with no obvious protective nature. Under these conditions, the pain may not only be amplified for a prolonged period of time by a stimulus (hyperalgesia) but may also spread to other unaffected sites distant from the zone of injury (secondary hyperalgesia). It can also be triggered by apparently innocuous stimuli such as touch (allodynia) and may even appear spontaneously with no obvious triggering factor or after an initial stimulus has disappeared or been eliminated such as following the clinical and/or surgical treatment of endometriosis. ${ }^{25}$ One of the key events associated with these conditions is central sensitization (CS). This consists of a series of dysfunctions in the central nervous system (CNS), including alterations in afferent sensory processing and changes in excitatory and inhibitory mechanisms. In women with CPP, a series of morphological and functional changes occurs in the CNS that favors the occurrence of these events. ${ }^{25}$ From a clinical point of view, as first described in the 1980s, CS represents an increase in the neural signaling of the nociceptive pathways within the CNS. ${ }^{26}$ Unlike peripheral sensitization, CS is the result of phenotypic changes in the neurons of the CNS so that pain is no longer obligatorily dependent on peripheral stimulus, ie it becomes capable of maintaining and perpetuating itself, thus supporting some allegations that in these conditions the pain itself is a disease and no longer merely a symptom. ${ }^{10,27}$

Early recognition of the symptoms of CS in patients with chronic pain facilitates the implementation of better-targeted treatments with possibly better outcomes. Therefore, in 2017, the IASP introduced a third mechanistic pain descriptor with the term nociplastic pain defined as 
pain that arises from altered nociception despite no clear evidence of actual or threatened tissue damage causing the activation of peripheral nociceptors or evidence for disease or lesion of the somatosensory system causing the pain.

The IASP also adds that "patients can have a combination of nociceptive and nociplastic pain" ${ }^{18}$ From a practical viewpoint, nociplastic pain is pain experienced by patients whose clinical condition is dominated by symptoms associated with CS including "bad feelings" such as sleep disturbance, fatigue, anxiety, dizziness, nausea, emotional lability and cognitive problems. ${ }^{28}$ Nonetheless, there is an urgent need to establish precise clinical and psychometric criteria. $^{29}$

There is also a group of patients with chronic pain and significant psychiatric symptoms who do not fit into the classifications of nociceptive, neuropathic or nociplastic pain. ${ }^{28}$ In clinical practice, these conditions are often labeled as psychogenic but this can lead to even more confusion and reinforce a pejorative idea in patients, particularly women with CPP. The terminology is not homogenous and even less is known with respect to the physiopathology of these causes of pain. Potentially, they originate from damage to the functioning of the suprathalamic structures. Although this type of pain is indeed of neurological origin, it also has characteristic signs and symptoms. ${ }^{30}$ Using exclusion criteria, it could be classified as pain of unknown origin or idiopathic pain. ${ }^{28}$

There is evidence of a reciprocal and intertwined network of interaction between the CNS, the immune system and the endocrine system, which may contribute, peripherally and centrally, to pain modulation. ${ }^{31-33}$ Accordingly, a complex interaction has been reported between the glia (microglia, astrocytes and oligodendrocytes), endothelial cells, perivascular macrophages and T cells. ${ }^{34,35}$ Indeed, one hypothesis for the maintenance of CS is deregulation of the glial function within the $\mathrm{CNS}^{36}{ }^{36}$ Some authors agree that, after an initial immune challenge, the microglia are able to maintain increased transcriptional activity or epigenetic changes that confer a potentiated response to subsequent challenges that could include stress, lesions, diseases and aging. ${ }^{37}$ Moreover, various immune cells (mast cells, macrophages, neutrophils, $\mathrm{T}$ and $\mathrm{B}$ cells), both those residing locally in the tissues and those recruited peripherally, contain inflammatory mediators and precursors stored in cytoplasmic granules that can be released or activated under certain circumstances, possibly leading to hyperalgesia. These cells appear crucial in the physiopathology of various diseases associated with CPP such as endometriosis, ${ }^{38-42}$ interstitial cystitis/bladder pain syndrome (BPS) ${ }^{43-46}$ and irritable bowel syndrome (IBS). ${ }^{47-51}$ Recent studies have shown that immune cells are also involved in neuropathic pain. ${ }^{52-54}$ Additionally, in women, glial reactivity modulated by sex hormones, particularly estrogen, could contribute to a predominance of persistent pain and be associated with conditions such as endometriosis, inflammatory bowel disease and BPS. ${ }^{55}$ Finally, the nervous system, endocrine system and immune system have constant connectivity, which makes them react in an extremely orchestrated manner to the different stressors involved in the different types of chronic pain. ${ }^{33}$

\section{Diagnostic Evaluation}

The diagnostic evaluation of women with CPP is difficult, both because of its multifactorial etiology and because of the overlapping symptoms. This may explain the fact that around $60 \%$ of these women never receive an exact diagnosis and approximately $20 \%$ are not even submitted to any investigation to explore the cause of their pain. ${ }^{56}$

The National Institutes of Health (NIH) recognize a group of chronic overlapping pain conditions (COPCs) that have $\mathrm{CS}$ as the common mechanism. These include fibromyalgia, IBS and BPS, among others. ${ }^{57}$ One of these conditions could function as a triggering factor for another, even if one was of visceral origin and the other of somatic origin. ${ }^{58}$ There appears to be a phenotype for CS that is clinically characterized in individuals who present with unpleasant sensory experiences disproportionate to any observable peripheral cause. ${ }^{57}$ As discussed in this review, CPP, which is associated with a frequency of psychosomatic symptoms that is up to eight times greater than in asymptomatic controls, could be included in this group of COPCs and could be considered a functional somatic syndrome together with these other conditions. ${ }^{13}$

Identifying potential peripheral and organic causes of CPP through anamnesis, physical examination and supplementary tests remains an important goal. Nevertheless, maintaining an exclusive focus on these aspects could delay treatment and prolong the pain. ${ }^{59}$ Therefore, recognizing the phenotypic clinical conditions of CS both when taking the patient's history and at physical examination should be part of the diagnostic work-up of women with CPP. ${ }^{60-62}$ This approach 
could have an impact on the relevant treatment ${ }^{63,64}$ and could save time, effort and resources with diagnostic tests and surgical procedures that are often unnecessary. ${ }^{61,65}$

\section{Anamnesis}

Considering that these are women who have generally suffered pain over several years and who often feel frustrated with the results of their treatment, careful listening through a meticulous initial anamnesis and a physical examination that should be more detailed than a normal gynecological examination are recommended. ${ }^{66}$ Furthermore, there appears to be a consensus that psychosocial aspects associated with women with CPP should be evaluated. ${ }^{60,65}$ The collection of these data should be systematized, taking possible physiopathological mechanisms into consideration. Not doing so can result in further confusion, failed treatment and discouragement, both for the patients and for the healthcare professionals. ${ }^{60,66}$

The characteristics of the pain should be addressed during anamnesis, including its duration, frequency, quality, location, irradiation and intensity. Likewise, clinical markers that improve and/or worsen the pain such as nausea, vomiting, fever, urinary and bowel symptoms should be investigated, as well as the relationship between the pain and the menstrual cycle and the pain and sexual activity. ${ }^{66}$ This may shed light on possible etiologic factors, comorbidities and the severity of the clinical condition. If the pain worsens cyclically, this is important information, since it identifies a group of women who could benefit from the induction of amenorrhea. ${ }^{67,68}$

The way in which the patient describes the site of the pain can be extremely helpful. Visceral pain should be suspected if the patient runs her finger over a site instead of pointing to a specific spot or if she uses various fingers instead of just one to indicate the site of pain. On the other hand, in clinical practice, when the patient points a finger repeated times to a specific site, this is suggestive of somatic pain. Neuropathic pain is suspected when the site indicated by the patient corresponds to a specific dermatome. ${ }^{69,70}$

Alternatively, the patient could point out the site of pain on a body chart. ${ }^{69}$ Although these are not diagnostic criteria, particularly because of the frequent overlapping of symptoms in cases of CPP, the positions indicated on body charts may serve as a guide during investigation. In clinical practice, a check mark or an $\mathrm{X}$ at a specific point may indicate typically somatic pain, while shadowed areas below the umbilicus may suggest visceral pain, and marks outlining a dermatome may be a sign of neuropathic pain. However, there can be a combination of more than one type of pain.

The intensity of the pain at the time of the clinical visit and in the preceding two weeks can be determined using a 10$\mathrm{cm}$ visual analogue scale (VAS) in which 0 represents the absence of pain and 10 the worst pain experienced by the patient. ${ }^{66}$ Nevertheless, pain has psycho-affective components and in many cases the true extent of suffering experienced by a woman with CPP is not registered if only the VAS is used. ${ }^{71}$ Graphic representation of pain using either shapes or colors can be a strategy for registering its psycho-affective component. Drawings illustrating negative feelings, harmful instruments and a predominance of cold colors (those from the blue-green spectrum, neutral colors and the grey spectrum) have been described in the literature. ${ }^{71}$ The McGill Pain Questionnaire, although extensive, could be particularly useful in certain situations, since the descriptors of pain help legitimize the symptom experienced by the women. $^{72}$

In relation to CS, the Central Sensitization Inventory (CSI) ${ }^{62}$ a two-part self-report scale, can be extremely useful. Part A of the CSI contains 25 items on current symptoms, with a cut-off score of 40 on a total score that ranges from 0 to 100 representing a strong possibility of the presence of a central sensitivity syndrome (CSS) ${ }^{61}$ Part B of this inventory consists of 10 items that question whether a doctor has already diagnosed the individual with one or more of the seven specific disorders comprising the CSS family and/or certain associated conditions such as anxiety and depression. ${ }^{62}$ More recently, a short version of the CSI containing nine items (CSI-9) was proposed for patients with musculoskeletal pain, ${ }^{73}$ with 20 being the cut-off point in this version for symptoms of CS. ${ }^{74}$ In view of the shorter time required to complete the instrument, future studies using the CSI-9 for other health conditions such as CPP could encourage its use in a clinical setting.

Considering the lack of any simple means of identifying CS in chronic pelvic and perineal pain (PP), a clinical evaluation tool referred to as the Clinical Criteria of Central Sensitization in Chronic Pelvic and Perineal Pain (Convergences PP Criteria) was elaborated, based on an expert consensus. ${ }^{60}$ Factors taken into consideration include questions on the relationship between the pain and urination, defecation and sexual activity, variability in the intensity 
and distribution of the pain, and the presence of comorbidities such as migraine, fibromyalgia, multiple chemical sensitivity and others. Although this instrument is unable to establish a diagnosis, it constitutes an excellent guide in clinical practice, with more than 5 positive answers out of a total of 10 being suggestive of CS. ${ }^{60}$

The presence of pain hypersensitivity (sensitivity to touch and/or to pressure and/or to motion and/or to hot or cold temperatures) and at least one of the following comorbidities: heightened sensitivity to sound and/or light and/or odors, sleep disorders including waking frequently during the night, fatigue, and cognitive problems such as difficulty concentrating, memory abnormalities, etc. can be considered suggestive of nociplastic pain. ${ }^{28}$ Although the IASP guidelines do not directly propose use of the CSI, many of its items were taken into consideration in the investigation of allodynia and of the comorbidities mentioned, with its application for the identification of CS being more practical for day-to-day use. ${ }^{29}$

Figure 2 consists of a flowchart listing the clinical criteria suggestive of CS in women with CPP. Nociplastic pain can be associated with neuropathic pain and with non-neuropathic pain.

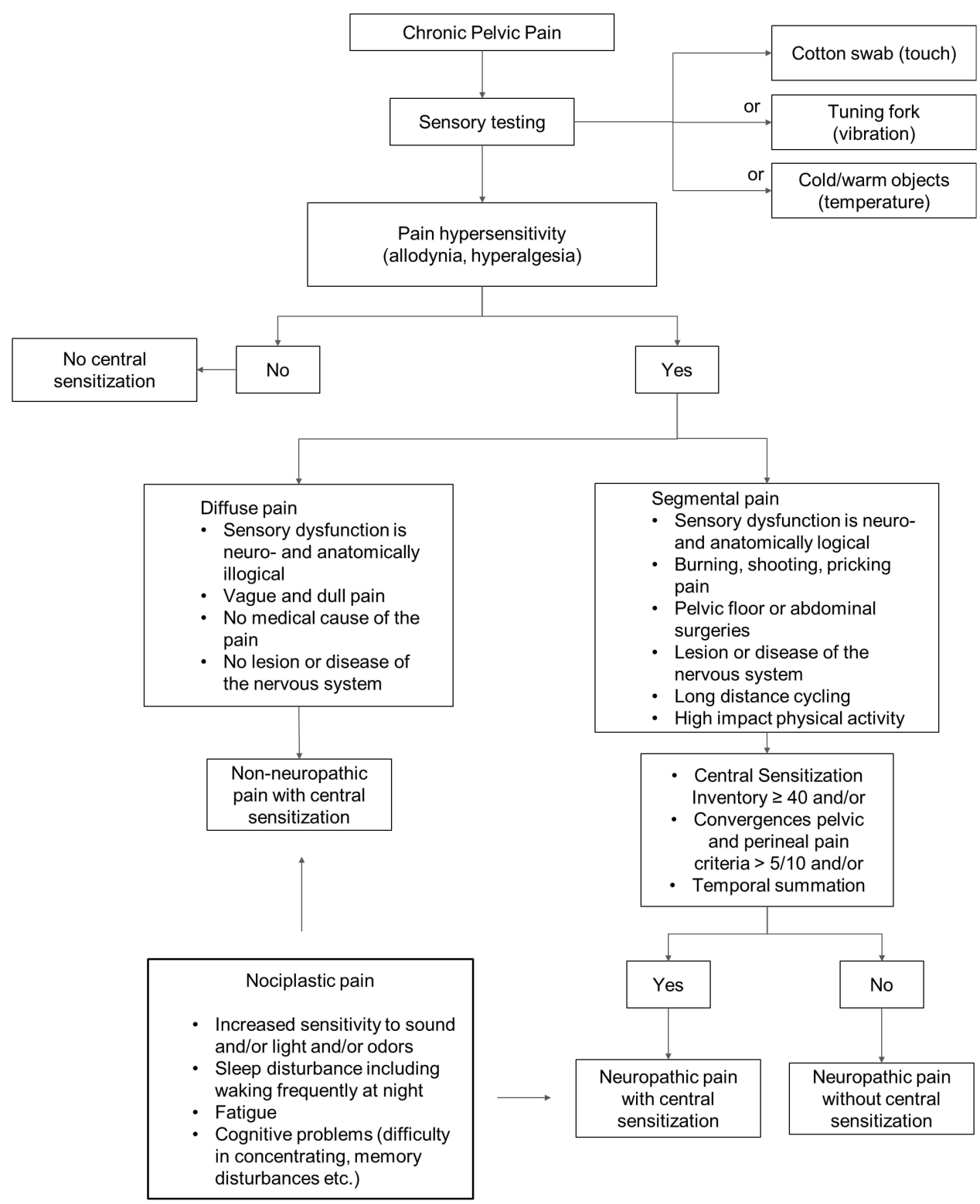

Figure 2 Flowchart of the clinical criteria suggestive of central sensitization in women with chronic pelvic pain. 


\section{Psychosocial Evaluation}

The experience of pain in general is currently understood as an interdependent sum of biological, psychological and social factors. ${ }^{75}$ In the case of CPP, there is strong evidence on the role of psychosocial factors. ${ }^{8,65,76}$

Coexistence between chronic pain and mental disorders has been widely reported in the literature, with these conditions being more prevalent in women. ${ }^{77-79}$ There is increasingly robust biological evidence on the bidirectional relationship of these conditions, with each condition tending to exacerbate the other. Functional magnetic resonance imaging (MRI) shows an overlap in the neural circuits that are activated in situations of pain and in negative mood states. ${ }^{77,78}$ The neurotransmitters involved in these conditions, including serotonin, gamma-aminobutyric acid, glutamate, noradrenaline, dopamine, etc., are also shared. ${ }^{80}$ Trait anxiety, trait sensory hypersensitivity and the defensive high anxious personality type have been associated with the extent of symptoms in CS in individuals with chronic low back pain $^{81}$ and these findings could possibly be extrapolated in the future to women with CPP. Trait anxiety has already been associated with chronic pain following Cesarean section. ${ }^{82}$ Despite the limitations involved in determining the order in which the manifestations begin and in establishing a cause-effect relationship, the prognosis of patients with CPP is guarded when these aspects are not taken into consideration in conjunction. ${ }^{79,83,84}$

The three emotional conditions most commonly found in individuals with chronic pain in general are anxiety, depression and anger. ${ }^{57} \mathrm{~A}$ high frequency of anxiety, depression ${ }^{79,83,85}$ and of mixed anxiety and depressive disorder ${ }^{85}$ has been described in women with CPP. The prevalence of adverse childhood events (ACE), including sexual, physical${ }^{85-87}$ and emotional abuse, ${ }^{86,87}$ is also high in these women. Furthermore, the association between ACE and mental disorders in women with CPP is consistent ${ }^{76,79,87}$ and should be taken into consideration in clinical practice. Physical or sexual abuse in adult life has also been associated with CPP as well as with anxiety, depressive mood, somatization, posttraumatic stress disorders ${ }^{88}$ and pain-related disability. ${ }^{76}$ In addition, women with CPP and a history of sexual abuse are reported to experience more severe pain ${ }^{89}$ and efforts to reduce the intensity of pain tend to be less successful. ${ }^{67}$

Other social stressors such as the death or illness of family members, ${ }^{67,88}$ poor education level $^{76,88}$ and unemployment ${ }^{87}$ are also factors that have been associated with CPP. In fact, over $70 \%$ of women with CPP report some event that coincides with the onset of the pain, with a history of marital and/or family conflicts, traumas and obstetric events often being mentioned. ${ }^{67}$ A poorer prognosis in the case of women with CPP has been associated with maladaptive thinking, beliefs about pain (catastrophic thinking), ${ }^{83,89}$ and lower pain self-efficacy, ${ }^{83}$ either due to magnification of the pain symptom, poorer compliance with the proposed treatment or fewer coping behaviors. On the other hand, religiosity has been positively associated with quality of life in women with CPP. ${ }^{90}$ Further studies are necessary to investigate psychological variables ${ }^{65,83}$ religiosity and spirituality ${ }^{90}$ in women with CPP.

In general, women with CPP have a poorer perception of their quality of life, ${ }^{91}$ precisely because CPP involves negative repercussions in the emotional, sexual, behavioral, relational, cognitive and professional spheres. Therefore, the investigation of psychosocial factors in women with CPP has been recommended in the guidelines of several associations such as the ACOG (2020), ${ }^{8}$ the Society of Obstetricians and Gynaecologists of Canada, ${ }^{66}$ the International Society of Psychosomatic Obstetrics and Gynaecology, ${ }^{88}$ the Royal College of Obstetricians and Gynaecologists ${ }^{92}$ and the European Association of Urology. ${ }^{93}$ The use of self-administered questionnaires to be completed by the patients in the waiting room prior to medical consultation or even during consultation has been suggested. .,65,66 $^{-6}$

Of the various instruments aimed at investigating anxiety, the Generalized Anxiety Disorder-7 (GAD-7) has often been used in studies. It is a short, 7-item self-report questionnaire that indicates the presence of symptoms of anxiety in the preceding two weeks. ${ }^{94}$ One option for the investigation of depression is the 9-item Patient Health Questionnaire (PHQ-9), which investigates the presence of depressive symptoms in the preceding two weeks and is based on the diagnostic criteria for major depression listed in the Diagnostic and Statistical Manual of Mental Disorders, fourth edition (DSM-IV). ${ }^{95}$ Another option is the Hospital Anxiety and Depression Scale (HADS), a 14-item self-report scale in which seven of the items deal with anxiety (HAD-A) and seven with depression (HAD-D). ${ }^{96}$ The choice of the most appropriate instrument for women with CPP should be guided by, among other factors, the objectives behind the investigation (research or clinical practice), the characteristics of the population, and the existence of translated, culturally adapted and validated versions of the instrument. 
The Pain Catastrophizing Scale (PCS) is the instrument suggested to identify catastrophizing. PCS is a 13-item tool with three different domains: rumination, magnification and helplessness. ${ }^{97}$ A cut-off score $\geq 30$ is considered indicative of catastrophizing behavior. ${ }^{98}$ Attention should be paid to sexual function when conducting an anamnesis of women with $\mathrm{CPP},{ }^{66}$ since, according to a previous report, $81 \%$ may present with sexual dysfunction. ${ }^{68}$

In relation to CS, psychological aspects were not included in Part A of the CSI ${ }^{62}$ perhaps because the sensitivity and specificity of this instrument are poor in relation to this condition. ${ }^{69}$ Nevertheless, the authors appear to recognize the importance of these issues by having included anxiety/panic attacks and depression in Part B of the CSI. ${ }^{62}$

The psychometric instruments mentioned, as well as many others reported in the literature, can be used both at the initial medical consultation to enable diagnosis to be reached and sporadically thereafter during the follow-up of women with CPP to monitor prognosis and outcome. ${ }^{89}$

Another option is to investigate, within the scope of the clinical interview, topics such as quality of life, sexual function, beliefs regarding pain, strategies for dealing with pain, family, social and religious support networks, and the impact of pain on an individual's professional life. ${ }^{8,65,66,90}$ The most important factor for a woman with CPP may be feeling that her complaints are being taken seriously and that she is being listened to, not necessarily through the use of previously validated instruments. Because CPP is a condition that requires long term monitoring, ${ }^{99}$ more delicate subjects such as sexual function and a history of sexual abuse can be gradually addressed at future consultations when the relationship of trust between the healthcare professional and the patient has already been established. ${ }^{65}$

\section{Physical Examination}

Since the physical examination should be more detailed than a routine gynecological examination, it has been suggested that it should be performed at a second appointment, giving the patient plenty of time to report the history of her pain during the first consultation. ${ }^{66}$

With the possible primary causes and comorbidities associated with CPP in mind, the examiner should evaluate visceral, musculoskeletal and neurological aspects using visualization, bimanual palpation, mobilization of structures, speculum examination, and digital vaginal and/or rectal examination. ${ }^{65}$ Pain at abdominal palpation that is exacerbated when the rectus abdominis muscles are contracted is suggestive of somatic pain, while visceral pain tends to decrease or remain unchanged when the head or the lower limbs are raised. ${ }^{8}$ Notwithstanding, the physical examination tends to be normal in the majority of women with CPP, with the patient referring only discomfort during examination. This subjective finding is expected, since the patient is already in pain prior to palpation. More specific findings at physical examination are most commonly related to endometriosis. ${ }^{67}$ Endometriosis can be identified as nodules on the abdominal wall in the proximity of a Cesarean scar or as the cause of reduced mobility of the uterus and adnexa, as ovarian cysts, or as lesions on the uterosacral ligaments and rectovaginal septum. ${ }^{100,101}$

Signs of CS can be identified at physical examination without the use of any sophisticated devices or methods. The presence of allodynia is simple to detect by gently stroking a brush or cotton swab (Q-tip) or a metal object at room temperature over the area where the patient reports pain and asking the patient about the resulting experience. ${ }^{28}$ Abdominal and perineal cutaneous allodynia may discriminate visceral pain from somatic pain. ${ }^{102}$ Some authors have suggested routine investigation of hypersensitivity (pressure hyperalgesia) of the pelvic floor in women with CPP as indicative of CS by performing an internal single digit exam at the bilateral pubococcygeus, iliococcygeus and coccygeus muscles. ${ }^{103}$ More sensitive quantitative tests can be used in cases in which CS is not so obvious. In this respect, temporal summation, a marker of CS, can be investigated using a bedside test in which a cotton swab (Q-tip) is successively stroked down the abdomen from the infracostal margin in the midclavicular line to the groin. The test is considered positive if the pain worsens significantly with successive stimuli. ${ }^{63,104}$ Hypersensitivity at sites that are distant from the clinical site of pain can be investigated using Quantitative Sensory Testing (QST) ${ }^{105}$ and appears to be a sign of CS that is typically present in nociplastic pain. ${ }^{28}$ In women with CPP, non-pelvic pressure pain sensitivity can be evaluated using an algometer on the non-dominant thumbnail, as previously reported. ${ }^{103}$ 


\section{Supplementary Tests}

The use of laboratory and imaging tests is limited in CPP and tests should be requested on an individualized basis, taking into consideration the symptoms of each individual patient and the findings at physical examination. ${ }^{8,65}$ Consequently, the parsimonious use of diagnostic tests to identify coexisting diseases appears to be a consensus among groups of specialists in $\mathrm{CPP}^{8,66}$ with screening for vaginitis and sexually transmitted infections, for instance, being performed if risk factors for these diseases are present, ${ }^{8}$ and urinalysis and urine culture being requested only in the presence of urinary symptoms. $^{65}$

The presence of pelvic tumors can be investigated using transvaginal ultrasonography (TVUS), a simple, inexpensive test with sensitivity and specificity similar to those of pelvic MRI when performed by experienced professionals. ${ }^{106}$ Even deep endometriosis, endometriosis of the rectovaginal septum, and retrocervical, bowel and bladder endometriosis can be diagnosed using TVUS, with or without prior bowel preparation. ${ }^{107}$ Neither MRI nor the cancer antigen 125 (CA-125) test should be used as routine for the purpose of diagnosing endometriosis. ${ }^{108}$

Colonoscopy should be requested only when there is a history suggestive of bowel disease ${ }^{8}$ or when the patient is $\geq$ 45 years old. ${ }^{109}$ Diagnostic laparoscopy is increasingly considered second-line for the investigation of CPP in women and should only be requested for cases involving organ abnormalities such as, for example, ovarian cysts, hydrosalpinx, etc. ${ }^{92}$ In close to $40 \%$ of patients, no verifiable abnormality is found at laparoscopy and when adhesions and/or endometriosis are detected, and surgical interventions are performed, the outcome tends to be unsatisfactory. ${ }^{65,110,111}$

Although its applicability remains impractical, it is worth mentioning that orthostatic intolerance to the tilt-table test is compatible with central hypervigilance and is suggestive of CS, and perhaps of catastrophizing in women with CPP. ${ }^{112}$

\section{Treatment}

The treatment of CPP is challenging and not always effective, with most of the available guidance being based on other forms of chronic pain and lacking the endorsement of strong scientific evidence. ${ }^{8,65,66,92,100,113}$ The treatment of potentially pain-causing conditions is imperative. In relation to COPCs, it has been shown that the treatment of pain of visceral origin can alleviate another form of pain even if it is of somatic origin, reinforcing the need to treat comorbidities in women with CPP. ${ }^{58}$ Nevertheless, therapies aimed at reducing the perception of pain or at treating the events associated with the chronification of pain as a disease (CS for example) should be considered. ${ }^{66}$ Different society guidelines recommend a multimodal treatment regimen aimed at maximizing the risk-benefit ratio. ${ }^{8,66,92}$

\section{Non-Pharmacological Treatment}

\section{Pain Neuroscience Education}

Patients naturally tend to worry about uterine and ovarian diseases that are not necessarily the cause of $\mathrm{CPP}^{65,67}$ Therefore, physician-patient communication should be effective in making it clear that the woman's concerns are being taken seriously and that the biological aspect is not being neglected; that the pain they experience is real and not imaginary, ruling out a primary mental disorder; ${ }^{114}$ that their emotions and thoughts in relation to the pain affect the way in which they deal psychologically with the problem and which, biologically, can influence pain-excitatory pathways; ${ }^{98}$ and finally, that adverse life experiences and psychological and/or relational conflicts matter, since they can predispose, precipitate and/or perpetuate the pain, particularly pain involving CS. ${ }^{114}$

Pain neuroscience education (PNE) has been added to the usual forms of treatment, contributing towards reducing the intensity and catastrophizing of pain. ${ }^{8,65,66,98,115}$ Some authors have suggested a practical guide for PNE when dealing with women with CPP that includes an explanation on pain mechanisms (P) and on the different factors associated with pain: somatic (S), cognitive (C), emotional (E), behavioral (B) and social (S), as well as a discussion with the patient on motivation (M) for treatment (the PSCEBSM model). ${ }^{98}$ Effective physician-patient communication should highlight the fact that the management of chronic pain requires long-term treatment, that the condition involves an important biopsychosocial cornerstone and requires changes in lifestyle, meaning that the woman has to play an active role in her treatment. ${ }^{65,98}$ 


\section{Psychotherapy}

Although it is already recognized that the approach required in cases of CPP has to be interdisciplinary and must include psychosocial aspects, ${ }^{8,65}$ randomized clinical trials involving psychological interventions in women with this condition remain scarce. Mindfulness-based stress reduction and cognitive-behavioral therapy has been suggested for other types of chronic pain ${ }^{116,117}$ as well as for CPP in women. ${ }^{89}$ The outcomes, however, appear to be better when these treatments are aimed at training individuals to change their way of thinking and their attitudes towards pain, particularly when the objective is decreasing pain catastrophizing ${ }^{89,117}$ and increasing patient self-efficacy at managing pain. ${ }^{117}$

Considering the high prevalence of ACE and mental disorders in women with CPP ${ }^{85-87}$ family constellation ${ }^{118}$ could be an interesting option for these patients, since a significant reduction in the intensity of CPP in women has already been shown with this approach. ${ }^{67}$

\section{Neuromodulation}

The central and neurosensorial mechanisms of pain have been studied as approaches for the management of chronic pain refractory to conventional treatments, with spinal cord stimulation (SCS) and dorsal root ganglion stimulation (DRGS) appearing the most promising. ${ }^{19-123}$ Different studies have reported a reduction in pain, an improvement in quality of life and a reduction in the use of opioids in patients with chronic pain and CPP submitted to treatments involving DRGS and SCS (Table 1). Nevertheless, small sample sizes and the poor quality of scientific evidence have limited conclusions regarding the actual efficacy of these approaches in the treatment of CPP and other forms of chronic pain. ${ }^{124}$ Therefore, despite studies showing the important role of CS in the physiopathology of CPP, intervention strategies based on these mechanisms are not yet well established in the scientific community.

\section{Dietary Measures and Physical Activity}

Changes in diet can prevent symptoms from becoming worse, particularly in patients with IBS or BPS. Lactose and/or fructose intolerance can be associated with IBS, and recommendations include controlling consumption of these substances. ${ }^{66}$ In addition, fermentable oligosaccharides, disaccharides, monosaccharides, polyols, caffeine, alcohol and gluten should be temporarily avoided, particularly when associated with the aggravation of IBS symptoms, and the benefits of this restriction should be evaluated on an individualized basis. ${ }^{66,125}$ In patients with BPS, recommendations include monitoring the dietary consumption of tomatoes, soya, condiments, pepper, caffeine, foodstuffs rich in sodium and citric fruits. ${ }^{126}$

The World Health Organization (WHO) recommends aerobic physical activity of moderate intensity for at least 150 minutes/week, which has been shown to provide general health benefits and can reduce anxiety and depression, relevant comorbidities associated with CPP. ${ }^{127}$ Nevertheless, there is still no strong scientific evidence confirming the effectiveness of exercise on chronic pain in adults or on endometriosis-related pain. ${ }^{128,129}$

\section{Pharmacological Treatment}

Pharmacological recommendations for CPP are based more on expert opinions than on randomized clinical trials. ${ }^{8,66,92,100,113}$ Non-steroidal anti-inflammatory drugs (NSAIDs) are commonly used empirically as the first-line treatment of CPP, 5,68,100 particularly during flare-ups involving increasing pain levels, in view of their accessibility, tolerability, low cost and familiarity to patients.

The uninterrupted use of progestogens or of combined oral contraceptive (COC) pills to induce amenorrhea can be initiated early in cases when pain tends to worsen cyclically, which occurs in $81 \%$ of cases of CPP. ${ }^{15}$ The benefit achieved with this treatment is expected, irrespective of whether or not there are signs of endometriosis present. ${ }^{66-68}$ The progestogens most commonly used in clinical practice are norethisterone, desogestrel, dienogest and the levonorgestrelreleasing intrauterine system. ${ }^{100,130,131}$ The efficacy of the various progestogens is similar and the satisfaction rates of patients with CPP and endometriosis are around 70\%; however, norethisterone may be the progestogen of choice in view of its lower cost. ${ }^{130}$ Medroxyprogesterone acetate is also an option, preferentially in the form of the three-monthly injection. ${ }^{131}$ Conversely, use of GnRH agonists is limited, since they cannot be used over the long term because of their 
Table I Studies on Neuromodulation in the Management of Chronic Pain

\begin{tabular}{|l|l|l|l|l|l|l|}
\hline $\begin{array}{l}\text { Authors, } \\
\text { Year }\end{array}$ & Country & \multicolumn{1}{|c|}{ Design } & N & Type of Pain & Treatment & Main Results \\
\hline $\begin{array}{l}\text { Hunter \& } \\
\text { Yang, } \\
2019^{119}\end{array}$ & USA & Case series & 7 & $\begin{array}{l}\text { Chronic pelvic } \\
\text { pain }\end{array}$ & DRGS & Reduction of opioid use and pain relief in all patients. \\
\hline $\begin{array}{l}\text { Schu et al., } \\
2015^{120}\end{array}$ & Europe & Retrospective & 29 & Groin pain & DRGS & $\begin{array}{l}\text { Mean reduction in pain of } 71.4 \pm 5.6 \%, \text { with } 82.6 \% \text { of the } \\
\text { participants reporting a reduction in pain of }>50 \% \text { at the } \\
\text { last follow-up visit. }\end{array}$ \\
\hline $\begin{array}{l}\text { Levine } \\
\text { et al., } \\
2016^{121}\end{array}$ & Canada & Prospective & 15 & $\begin{array}{l}\text { Chronic groin, } \\
\text { pelvic and } \\
\text { abdominal pain }\end{array}$ & SCS & $\begin{array}{l}\text { Reduction in pain intensity from } 7.3 \pm 1.3 \text { to } 3.1 \pm 2.8,3.8 \\
\pm 2.4 \text { and } 4.2 \pm 3.2 \text { at } 3,6 \text { and } 12 \text { months, respectively. }\end{array}$ \\
\hline $\begin{array}{l}\text { Bridger } \\
\text { et al., } \\
2021^{122}\end{array}$ & USA & Prospective & 55 & $\begin{array}{l}\text { Neuropathic } \\
\text { pelvic pain }\end{array}$ & $\begin{array}{l}\text { DRGS and } \\
\text { SCS }\end{array}$ & $\begin{array}{l}\text { Satisfactory response in } 45.5 \% \text { of II patients in the } \\
\text { neuromodulation group versus } 26.6 \% \text { of } 44 \text { patients in the } \\
\text { clinical treatment group after } 25 \text { and } 33 \text { months, } \\
\text { respectively. }\end{array}$ \\
\hline $\begin{array}{l}\text { Deer } \\
\text { et al., } \\
2017^{123}\end{array}$ & USA & $\begin{array}{l}\text { Randomized } \\
\text { clinical trial }\end{array}$ & 152 & $\begin{array}{l}\text { Complex regional } \\
\text { pain syndrome } \\
\text { and causalgia }\end{array}$ & $\begin{array}{l}\text { DRGS and } \\
\text { SCS }\end{array}$ & $\begin{array}{l}\text { Reduction of } \geq 50 \% \text { in pain in } 81.2 \% \text { of the DRGS } \text { group } \\
\text { versus } 55.7 \% \text { of the SCS } \text { group after } 3 \text { months ( }<<0.00 I) .\end{array}$ \\
\hline
\end{tabular}

Abbreviations: DRGS, dorsal root ganglion stimulation; SCS, spinal cord stimulation.

high cost and side effects (hot flashes, vaginal dryness and osteoporosis), in addition to the fact that they need to be combined with add-back hormone replacement therapy ${ }^{66,132}$ A Cochrane review failed to find any reliable evidence on the use of COCs for the treatment of endometriosis-related pain. ${ }^{133}$ Nevertheless, various medical societies and different experts in CPP argue that COCs are effective in two-thirds of patients with CPP, particularly when used continuously, irrespective of whether endometriosis has been confirmed by laparoscopy or not. ${ }^{66,92,100,113}$

The tricyclic antidepressant amitriptyline has long been used in the treatment of fibromyalgia, BPS, IBS and CPP, particularly when associated with neuropathic pain, and anxiety and/or depression, despite a lack of robust scientific evidence. ${ }^{8,67,92,134-138}$ On the other hand, nortriptyline, imipramine and desipramine appear to be ineffective for the treatment of neuropathic pain. ${ }^{139-141}$

Antidepressants such as noradrenaline and serotonin reuptake inhibitors have been shown to have a positive effect on pain and on quality of life; however, their effect on depression is minimal and they have no effect at all on anxiety in patients with various types of neuropathic pain, as shown in a recent systematic review with meta-analysis that included 32 studies. ${ }^{142}$ Of this class of drugs, duloxetine at the dose of $60 \mathrm{mg}$ /day is able to reduce pain in patients with diabetic neuropathy and/or fibromyalgia ${ }^{143}$ and, although no studies have yet been conducted in women with CPP, duloxetine could be tried by inference when this pain is neuropathic. ${ }^{8}$

The indication of opioids for the treatment of women with CPP is controversial. On the one hand, their use may result in a return to normal activities for patients who have failed to respond to routine painkillers. ${ }^{66}$ On the other hand, the chronic use of opioids is associated with a greater risk of adverse events, tolerance, overdose and dependence, which led the Centers for Disease Control and Prevention (CDC) to recommend that their use should be avoided as first-line treatment or as routine therapy. ${ }^{8}$ In addition, evidence suggests more benefits with non-pharmacological treatment and with non-opioid pharmacological treatment when compared to the chronic use of opioids, including fewer side effects. ${ }^{144}$

A systematic review that included four randomized controlled trials and 469 participants showed that the anticonvulsant gabapentin reduced CPP in women after six months of use, with the principal side effects being dizziness and somnolence. ${ }^{145}$ In a Cochrane review that included 45 studies and 11,906 participants, pregabalin reduced pain by at least $30 \%$ in patients with diabetic and post-herpetic neuropathy at a dose of $300 \mathrm{mg} /$ day and in patients with post-traumatic 
neuropathic pain, whether classified as mixed or not, at a dose of $600 \mathrm{mg} /$ day, with similar side effects to those found with gabapentin. ${ }^{146}$ Extrapolating these data, pregabalin could be recommended for the treatment of CPP. ${ }^{8}$

The use of delta-9-tetrahydrocannabinol (THC), the active ingredient in Cannabis sativa, is controversial. Although the possibility of using it to manage chronic pain has motivated an increasing number of studies into its effects on the modulation of pain perception, different systematic reviews found poor quality evidence in support of the use of medicinal cannabis in the treatment of chronic non-cancer pain. ${ }^{147-150}$ In fact, these studies come with the recommendation to use cannabinoids as the third or fourth line of treatment when other analgesics and opioids have failed and warn of a lack of studies with better scientific evidence.

The different approaches to the treatment of CPP mentioned above could be applied to the conditions specified hereafter. Since they are conditions more commonly associated with target organs, some of the characteristics of their treatment will be presented in detail.

In a randomized study in which participants and pain evaluators were blinded to allocation group, performing laparoscopic adhesiolysis of pelvic and abdominal adhesions failed to result in any difference in pain scores and improvement to quality of life over one year of follow-up compared to not performing the procedure. ${ }^{110}$ Over a 12 year follow-up period, the group submitted to adhesiolysis had a poorer outcome in terms of pain-free time, the use of analgesics, number of medical consultations and the need for subsequent surgery. ${ }^{111}$ Therefore, no benefit is attributed to performing adhesiolysis in women with CPP.

In the therapeutic approach to endometriosis, inducing amenorrhea through the use of progestogens or COCs has been recommended, ${ }^{130,131,151}$ particularly for women who do not wish to become pregnant. Surgery may be recommended for cases that prove refractory to clinical treatment, in particular when ovarian endometriomas, endometrioma of the abdominal wall, bowel obstruction and/or ureteral obstruction are present. ${ }^{152}$ Hysterectomy with bilateral salpingooophorectomy is the most effective treatment for endometriosis-associated $\mathrm{CPP} ;{ }^{66}$ however, this procedure is the exception when all other options have failed. A Cochrane review that included 14 clinical trials and 1563 participants was unable to conclude whether laparoscopic surgery for minimal to severe endometriosis improves pain in women with CPP. Further studies are required to compare laparoscopic interventions with clinical and lifestyle interventions; nonetheless, data on the safety of these surgeries remain insufficient. ${ }^{153}$ Both the aromatase inhibitors and the promising oral gonadotropin-releasing hormone $(\mathrm{GnRH})$ receptor antagonists are possible treatment options. ${ }^{100,113}$

Trigger points on the abdominal wall are painful points in the musculature of this region. Although it has been suggested that the injection of local anesthetics, with or without corticoids, at these trigger points may be beneficial, the evidence in favor of their use is as yet insufficient. ${ }^{8,66,92}$ A double-blind, randomized clinical trial with 80 women showed a beneficial effect of injections of a local anesthetic after 1-4 applications; however, no benefit was obtained with the addition of botulinum toxin after 60 days. ${ }^{154}$

Myofascial physical therapy, a pelvic floor-focused treatment, was found to result in a reduction in psychological distress and in pain intensity over a 9-month follow-up time in women with CPP associated with BPS and provoked vestibulodynia in a non-randomized prospective study without a true control group and with a small sample size. ${ }^{155} \mathrm{~A}$ systematic review covering the period from 2000 to 2019 included four randomized clinical trials (RCTs), although three were considered of only poor to moderate quality. ${ }^{156}$ According to the results, physiotherapy for pelvic floor muscle spasms was shown to be beneficial in women with CPP except in patients with BPS. Therefore, although partially discordant, the data available up to the present moment suggest that pelvic floor physiotherapy (PFP) is another option to be offered as treatment for these women while we await the results of more robust studies on the subject.

The treatment of IBS depends on its clinical presentation, with symptoms consisting predominantly of constipation, diarrhea or mixed symptoms. ${ }^{157}$ In an overview of Cochrane systematic reviews, taking the poor quality of the primary studies into consideration, only antispasmodics and antidepressants appear to be beneficial of all the pharmacological treatments proposed, while psychological therapy would be the only beneficial treatment among the non-pharmacological interventions. ${ }^{158}$

According to a Cochrane review, there is insufficient evidence to endorse any of the 65 different treatments for BPS, which involve medication, behavioral therapy and physiotherapy. ${ }^{159}$ Nevertheless, despite the fact that the proposed treatments for this condition are far from ideal, measures involving neuroeducation and dietary measures are considered 


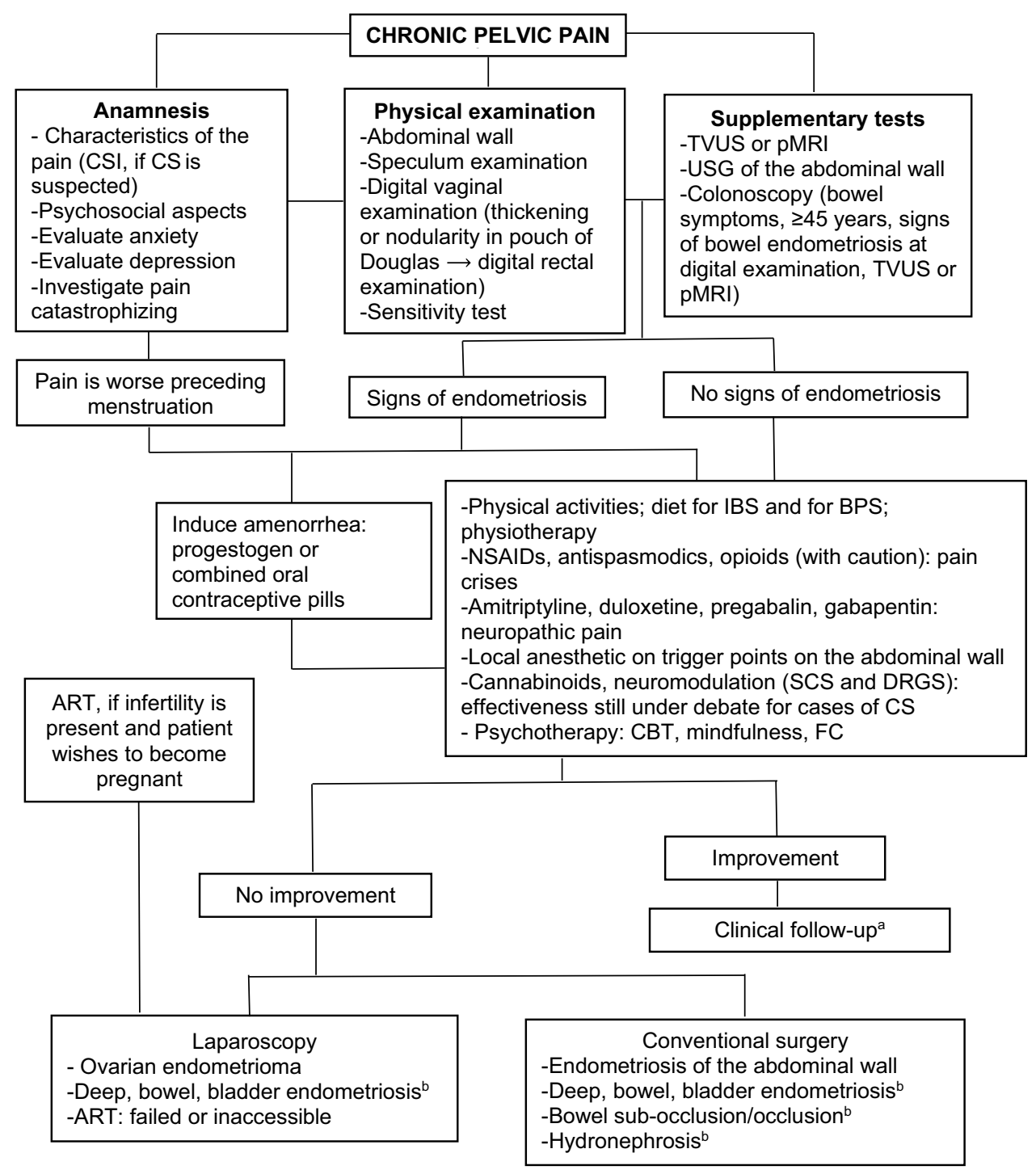

Figure 3 Management of women with chronic pelvic pain.

Notes: ${ }^{a}$ VAS: visual analogue pain scale (0-10). VAS $>3$ (quarterly), VAS $\leq 3$ (biannual; if stable over $\geq$ one year, end of follow-up); ${ }^{b}$ experience of the surgeon or multidisciplinary team.

Abbreviations: CSI, Central Sensitization Inventory; CS, Central sensitization; TVUS, Transvaginal ultrasonography; pMRI, Pelvic magnetic resonance imaging; USG, Ultrasonography; IBS, Irritable bowel syndrome; BPS, Bladder pain syndrome; NSAIDs, Non-steroidal anti-inflammatory drugs; SCS, Spinal cord stimulation; DRGS, Dorsal root ganglion stimulation; CBT, Cognitive behavioral therapy; FC, Family constellation; ART, Assisted reproductive techniques.

first-line. ${ }^{160}$ Amitriptyline, which is widely used and inexpensive, is a second-line option, with some analgesic, anticholinergic, sedative, anxiolytic and antidepressant effects, which could improve urinary frequency if the patient is able to tolerate at least $50 \mathrm{mg} /$ day. ${ }^{135}$

Figure 3 provides a summary of the principal aspects to be taken into consideration in the management of women with CPP.

\section{Conclusions}

$\mathrm{CPP}$ is an intriguing condition that may not be associated with an obvious cause and, even when a cause is identified, the extent of the disease is not always proportional to the intensity of the pain. The treatment of the peripheral disease only occasionally results in the cure or prolonged remission of the symptoms. Even so, a timely scheme of investigation and treatment of associated comorbidities is still recommended, with surgery being limited to extremely specific circumstances. Increasing efforts have been dedicated to understanding the physiopathological mechanisms involved in the 
cause and/or perception of pain and in the clinical recognition of CPP with the aim of offering physiopathology-based targeted therapies that will be effective over the long term. In this respect, early clinical identification of a phenotype for CS is possible and should be an aim, while perhaps relinquishing expensive tests and those of little clinical utility. The treatment of refractory chronic pain with neuromodulation appears promising; however, studies involving women with CPP are still sparse. Furthermore, it is vital that the team providing the treatment validates the patient's pain as a real symptom, establishing a relationship of trust with women who have often consulted with many doctors without feeling that they have been heard. PNE has proven extremely important in enabling patients to understand the various factors associated with pain and encouraging them to participate more actively in their treatment. PFP offers one more treatment option for women with CPP. The psychosocial approach is an important part of the treatment of women with CPP. Therapeutic techniques aimed principally at altering pain-related thoughts and behaviors, and those dealing with emotions associated with adverse life experiences and relationship conflicts, have been described in the literature. Results have been positive, even in relation to CS, and should encourage further in-depth studies. In view of the aforementioned factors, the treatment of CPP in women is challenging and personalized care within an interdisciplinary perspective is the best option.

\section{Author Contributions}

All authors made a significant contribution to the work reported, whether that is in the conception, study design, execution, acquisition of data, analysis and interpretation, or in all these areas; took part in drafting, revising or critically reviewing the article; gave final approval of the version to be published; have agreed on the journal to which the article has been submitted; and agree to be accountable for all aspects of the work.

\section{Funding}

This research received no external funding.

\section{Disclosure}

The authors declare that they have no conflicts of interest for this work.

\section{References}

1. Tripoli TM, Sato H, Sartori MG, de Araujo FF, Girão MJBC, Schor E. Evaluation of quality of life and sexual satisfaction in women suffering from chronic pelvic pain with or without endometriosis. J Sex Med. 2011;8(2):497-503. doi:10.1111/j.1743-6109.2010.01976.x

2. Nnoaham KE, Hummelshoj L, Webster P, et al. Impact of endometriosis on quality of life and work productivity: a multicenter study across ten countries. Fertil Steril. 2011;96(2):366-373.e8. doi:10.1016/j.fertnstert.2011.05.090

3. Mathias S. Chronic pelvic pain: prevalence, health-related quality of life, and economic correlates. Obstet Gynecol. 1996;87(3):321-327. doi:10.1016/0029-7844(95)00458-0

4. Huang G, Le A-L, Goddard Y, et al. A systematic review of the cost of chronic pelvic pain in women. J Obstet Gynaecol Can. 2021; S1701216321006952. doi:10.1016/j.jogc.2021.08.011

5. Chen I, Thavorn K, Shen M, et al. Hospital-associated costs of chronic pelvic pain in Canada: a population-based descriptive study. $J$ Obstet Gynaecol Can. 2017;39(3):174-180. doi:10.1016/j.jogc.2016.12.008

6. Armour M, Lawson K, Wood A, Smith CA, Abbott J. The cost of illness and economic burden of endometriosis and chronic pelvic pain in Australia: a national online survey. PLoS One. 2019;14(10):e0223316. doi:10.1371/journal.pone.0223316

7. Sharp HT, Johnson JV, Lemieux LA, Currigan SM. Executive summary of the reVITALize initiative: standardizing gynecologic data definitions. Obstet Gynecol. 2017;129(4):603-607. doi:10.1097/AOG.0000000000001939

8. Pain CP. Chronic Pelvic Pain: ACOG Practice Bulletin, Number 218. Obstet Gynecol. 2020;135(3):e98-109. doi:10.1097/ AOG.0000000000003716

9. Aziz Q, Giamberardino MA, Barke A, et al. The IASP classification of chronic pain for ICD-11: chronic secondary visceral pain. Pain. 2019;160(1):69-76. doi:10.1097/j.pain.0000000000001362

10. Treede R-D, Rief W, Barke A, et al. Chronic pain as a symptom or a disease: the IASP classification of chronic pain for the International Classification of Diseases (ICD-11). Pain. 2019;160(1):19-27. doi:10.1097/j.pain.0000000000001384

11. Latthe P, Latthe M, Say L, Gülmezoglu M, Khan KS. WHO systematic review of prevalence of chronic pelvic pain: a neglected reproductive health morbidity. BMC Public Health. 2006;6(1):177. doi:10.1186/1471-2458-6-177

12. Ahangari A. Prevalence of chronic pelvic pain among women: an updated review. Pain Physician. 2014;17(2):E141-E147. doi:10.36076/ ppj.2014/17/E141

13. Warren JW, Morozov V, Howard FM. Could chronic pelvic pain be a functional somatic syndrome? Am J Obstet Gynecol. 2011;205(3):199.e1199.e5. doi:10.1016/j.ajog.2011.04.003 
14. Ehlert U, Heim C, Hellhammer DH. Chronic pelvic pain as a somatoform disorder. Psychother Psychosom. 1999;68(2):87-94. doi:10.1159/ 000012318

15. Zondervan KT, Yudkin PL, Vessey MP, et al. The community prevalence of chronic pelvic pain in women and associated illness behaviour. $B r J$ Gen Pract. 2001;51(468):541-547.

16. Institute of Medicine (US) Committee on Pain, Disability, and Chronic Illness Behavior, ed. The Anatomy and Physiology of Pain. In: Pain and Disability: Clinical, Behavioral, and Public Policy Perspectives. Washington, D.C.: National Academies Press; Vol. 991, 1987.

17. Dubin AE, Patapoutian A. Nociceptors: the sensors of the pain pathway. $J$ Clin Invest. 2010;120(11):3760-3772. doi:10.1172/JCI42843

18. International Association for the Study of Pain (IASP). IASP Terminology; December 14, 2017 [cited 2021]. Available from: https://www.iasppain.org/terminology?navItemNumber=576\#Centralsensitization. Accessed February 8, 2022.

19. Sengupta JN. Visceral Pain: the neurophysiological mechanism. In: Canning BJ, Spina D, editors. Sensory Nerves (Handbook of Experimental Pharmacology). Berlin, Heidelberg: Springer Berlin Heidelberg; Vol. 194, 2009:31-74. Available from http://ink.springer.com/10.1007/978-3540-79090-7_2.

20. Marchand S. The physiology of pain mechanisms: from the periphery to the brain. Rheum Dis Clin North Am. 2008;34(2):285-309. doi:10.1016/j.rdc.2008.04.003

21. Gebhart GF, Bielefeldt K. Physiology of Visceral Pain. Compr Physiol. 2016;6(4):1609-1633.

22. Tu FF, Hellman KM, Backonja MM. Gynecologic management of neuropathic pain. Am J Obstet Gynecol. 2011;205(5):435-443. doi:10.1016/j. ajog.2011.05.011

23. Gangadharan V, Kuner R. Pain hypersensitivity mechanisms at a glance. Dis Model Mech. 2013;6(4):889-895. doi:10.1242/dmm.011502

24. Zhang X, Lu B, Huang X, Xu H, Zhou C, Lin J. Endometrial nerve fibers in women with endometriosis, adenomyosis, and uterine fibroids. Fertil Steril. 2009;92(5):1799-1801. doi:10.1016/j.fertnstert.2009.05.016

25. Brawn J, Morotti M, Zondervan KT, Becker CM, Vincent K. Central changes associated with chronic pelvic pain and endometriosis. Hum Reprod Update. 2014;20(5):737-747. doi:10.1093/humupd/dmu025

26. Woolf CJ. Evidence for a central component of post-injury pain hypersensitivity. Nature. 1983;306(5944):686-688. doi:10.1038/306686a0

27. Raffaeli W, Arnaudo E. Pain as a disease: an overview. J Pain Res. 2017;10:2003-2008. doi:10.2147/JPR.S138864

28. Kosek E, Clauw D, Nijs J, et al. Chronic nociplastic pain affecting the musculoskeletal system: clinical criteria and grading system. Pain. 2021;162(11):2629-2634. doi:10.1097/j.pain.0000000000002324

29. Nijs J, Lahousse A, Kapreli E, et al. Nociplastic pain criteria or recognition of central sensitization? Pain phenotyping in the past, present and future. J Clin Med. 2021;10(15):3203. doi:10.3390/jcm10153203

30. Toda K. The terms neurogenic pain and psychogenic pain complicate clinical practice. Clin J Pain. 2007;23(4):380-381. doi:10.1097/ AJP.0b013e31803b36dd

31. Zhu T-H, Ding S-J, Li T-T, Zhu L-B, Huang X-F, Zhang X-M. Estrogen is an important mediator of mast cell activation in ovarian endometriomas. Reproduction. 2018;155(1):73-83. doi:10.1530/REP-17-0457

32. Zouikr I, Karshikoff B. Lifetime modulation of the pain system via neuroimmune and neuroendocrine interactions. Front Immunol. 2017;8. doi:10.3389/fimmu.2017.00276

33. Chapman CR, Tuckett RP, Song CW. Pain and stress in a systems perspective: reciprocal neural, endocrine, and immune interactions. $J$ Pain. 2008;9(2):122-145. doi:10.1016/j.jpain.2007.09.006

34. Grace PM, Hutchinson MR, Maier SF, Watkins LR. Pathological pain and the neuroimmune interface. Nat Rev Immunol. 2014 ;14(4):217-231. doi: $10.1038 /$ nri3621

35. Baral P, Udit S, Chiu IM. Pain and immunity: implications for host defence. Nat Rev Immunol. 2019;19(7):433-447. doi:10.1038/s41577-019$0147-2$

36. Ji R-R, Berta T, Nedergaard M. Glia and pain: Is chronic pain a gliopathy? Pain. 2013;154(Supplement 1):S10-28. doi:10.1016/j. pain.2013.06.022

37. Kettenmann H, Hanisch U-K, Noda M, Verkhratsky A. Physiology of microglia. Physiol Rev. 2011;91(2):461-553. doi:10.1152/ physrev.00011.2010

38. Binda MM, Donnez J, Dolmans -M-M. Targeting mast cells: a new way to treat endometriosis. Expert Opin Ther Targets. 2017;21(1):67-75. doi:10.1080/14728222.2017.1260548

39. Hogg C, Horne AW, Greaves E. Endometriosis-associated macrophages: origin, phenotype, and function. Front Endocrinol. $2020 ; 11: 7$. doi: $10.3389 /$ fendo. 2020.00007

40. Symons LK, Miller JE, Tyryshkin K, et al. Neutrophil recruitment and function in endometriosis patients and a syngeneic murine model. FASEB J. 2020;34(1):1558-1575. doi:10.1096/fj.201902272R

41. de Barros IBL, Malvezzi H, Gueuvoghlanian-Silva BY, Piccinato CA, Rizzo LV, Podgaec S. What do we know about regulatory T cells and endometriosis? A systematic review. J Reprod Immunol. 2017;120:48-55. doi:10.1016/j.jri.2017.04.003

42. Riccio LGC, Baracat EC, Chapron C, Batteux F, Abrão MS. The role of the B lymphocytes in endometriosis: a systematic review. J Reprod Immunol. 2017;123:29-34. doi:10.1016/j.jri.2017.09.001

43. Ratner V. The importance of mast cells in interstitial cystitis/bladder pain syndrome. Transl Androl Urol. 2016;5(3):398. doi:10.21037/ tau.2016.03.19

44. Vera PL, Preston DM, Moldwin RM, et al. Elevated urine levels of macrophage migration inhibitory factor in inflammatory bladder conditions: a potential biomarker for a subgroup of interstitial cystitis/bladder pain syndrome patients. Urology. 2018;116:55-62. doi:10.1016/j. urology.2018.02.039

45. Kuromitsu S, Yokota H, Hiramoto M, Morita S, Mita H, Yamada T. Increased concentration of neutrophil elastase in urine from patients with interstitial cystitis. Scand J Urol Nephrol. 2008;42(5):455-461. doi:10.1080/00365590802025881

46. Moldwin RM, Nursey V, Yaskiv O, et al. Immune cell profiles and cytokine levels of patients with interstitial cystitis/bladder pain syndrome. Allergy Immunol. 2020. doi:10.1101/2020.12.17.20248414

47. Lee KN, Lee OY. The role of mast cells in irritable bowel syndrome. Gastroenterol Res Pract. 2016;2016:1-11. doi:10.1155/2016/2031480

48. Mahida YR. The key role of macrophages in the immunopathogenesis of inflammatory bowel disease. Inflamm Bowel Dis. 2000;6(1):21-33. doi:10.1097/00054725-200002000-00004 
49. Wéra O, Lancellotti P, Oury C. The dual role of neutrophils in inflammatory bowel diseases. J Clin Med. 2016;5(12):118. doi:10.3390/ jcm5120118

50. Öhman L, Isaksson S, Lindmark A-C, et al. T-Cell activation in patients with irritable bowel syndrome. Am J Gastroenterol. 2009;104(5):12051212. doi:10.1038/ajg.2009.116

51. Öhman L, Lindmark A-C, Isaksson S, et al. B-cell activation in patients with irritable bowel syndrome (IBS). Neurogastroenterol Motil. 2009;21(6):644-e27. doi:10.1111/j.1365-2982.2009.01272.x

52. Zuo Y, Perkins NM, Tracey DJ, Geczy CL. Inflammation and hyperalgesia induced by nerve injury in the rat: a key role of mast cells. Pain. 2003;105(3):467-479. doi:10.1016/S0304-3959(03)00261-6

53. Perkins NM, Tracey DJ. Hyperalgesia due to nerve injury: role of neutrophils. Neuroscience. 2000;101(3):745-757. doi:10.1016/S0306-4522 (00)00396-1

54. Moalem G, Xu K, Yu L. T lymphocytes play a role in neuropathic pain following peripheral nerve injury in rats. Neuroscience. 2004;129 (3):767-777. doi:10.1016/j.neuroscience.2004.08.035

55. Dodds KN, Beckett EAH, Evans SF, Grace PM, Watkins LR, Hutchinson MR. Glial contributions to visceral pain: implications for disease etiology and the female predominance of persistent pain. Transl Psychiatry. 2016;6(9):e888-e888. doi:10.1038/tp.2016.168

56. Cheong Y, William Stones R. Chronic pelvic pain: aetiology and therapy. Best Pract Res Clin Obstet Gynaecol. 2006;20(5):695-711. doi:10.1016/j.bpobgyn.2006.04.004

57. Williams DA. Phenotypic features of central sensitization. J Appl Biobehav Res. 2018;23(2):e12135. doi:10.1111/jabr.12135

58. Costantini R, Affaitati G, Wesselmann U, Czakanski P, Giamberardino MA. Visceral pain as a triggering factor for fibromyalgia symptoms in comorbid patients. Pain. 2017;158(10):1925-1937. doi:10.1097/j.pain.0000000000000992

59. Cheong YC, Smotra G, Williams AC. Non-surgical interventions for the management of chronic pelvic pain. Cochrane Database Syst Rev. 2014. doi:10.1002/14651858.CD008797.pub2

60. Levesque A, Riant T, Ploteau S, et al. Clinical criteria of central sensitization in chronic pelvic and perineal pain (Convergences PP Criteria): elaboration of a clinical evaluation tool based on formal expert consensus. Pain Med. 2018;19(10):2009-2015. doi:10.1093/pm/pny030

61. Neblett R, Cohen H, Choi Y, et al. The Central Sensitization Inventory (CSI): establishing clinically significant values for identifying central sensitivity syndromes in an outpatient chronic pain sample. J Pain. 2013;14(5):438-445. doi:10.1016/j.jpain.2012.11.012

62. Mayer TG, Neblett R, Cohen H, et al. The development and psychometric validation of the central sensitization inventory: validation of the central sensitization inventory. Pain Pract. 2012;12(4):276-285. doi:10.1111/j.1533-2500.2011.00493.x

63. Thompson HD, Tang S, Jarrell JF. Temporal summation in chronic pelvic pain. J Obstet Gynaecol Can. 2020;42(5):556-560. doi:10.1016/j. jogc.2019.09.012

64. Nijs J, Leysen L, Vanlauwe J, et al. Treatment of central sensitization in patients with chronic pain: time for change? Expert Opin Pharmacother. 2019;20(16):1961-1970. doi:10.1080/14656566.2019.1647166

65. Lamvu G, Carrillo J, Ouyang C, Rapkin A. Chronic pelvic pain in women: a review. JAMA. 2021;325(23):2381. doi:10.1001/jama.2021.2631

66. Jarrell JF, Vilos GA, Allaire C, et al. No. 164-Consensus guidelines for the management of chronic pelvic pain. J Obstet Gynaecol Can. 2018;40 (11):e747-87. doi:10.1016/j.jogc.2018.08.015

67. Deus JM, Santos AFR, Bosquetti RB, Pofhal L, Alves Neto O. Analysis of 230 women with chronic pelvic pain assisted at a public hospital. Rev Dor. 2014;15(3). doi:10.5935/1806-0013.20140042

68. Da Luz RA, de Deus JM, Valadares AL, Conde DM. Evaluation of sexual function in Brazilian women with and without chronic pelvic pain. $J$ Pain Res. 2018;11:2761-2767. doi:10.2147/JPR.S176851

69. Nijs J, Torres-Cueco R, van Wilgen CP, et al. Applying modern pain neuroscience in clinical practice: criteria for the classification of central sensitization pain. Pain Physician. 2014;17(5):447-457. doi:10.36076/ppj.2014/17/447

70. Mistry J, Heneghan NR, Noblet T, Falla D, Rushton A. Diagnostic utility of patient history, clinical examination and screening tool data to identify neuropathic pain in low back related leg pain: a systematic review and narrative synthesis. BMC Musculoskelet Disord. 2020;21(1):532. doi:10.1186/s12891-020-03436-6

71. Godoi JE, Reis DRM, Carvalho JR, Deus JM. Chronic pelvic pain portraits: perceptions and beliefs of 80 women. Braz J Pain. 2019;2(1):8-13. doi:10.5935/2595-0118.20190003

72. Melzack R, Raja SN. The McGill pain questionnaire. Anesthesiology. 2005;103(1):199-202. doi:10.1097/00000542-200507000-00028

73. Nishigami T, Tanaka K, Mibu A, Manfuku M, Yono S, Tanabe A. Development and psychometric properties of short form of central sensitization inventory in participants with musculoskeletal pain: a cross-sectional study. PLoS One. 2018;13(7):e0200152. doi:10.1371/ journal.pone. 0200152

74. Tanaka K, Nishigami T, Mibu A, et al. Cutoff value for short form of central sensitization inventory. Pain Pract. 2020;20(3):269-276. doi:10.1111/papr.12850

75. Gatchel RJ, Peng YB, Peters ML, Fuchs PN, Turk DC. The biopsychosocial approach to chronic pain: scientific advances and future directions Psychol Bull. 2007;133(4):581-624. doi:10.1037/0033-2909.133.4.581

76. As-Sanie S, Harris RE, Harte SE, Tu FF, Neshewat G, Clauw DJ. Increased pressure pain sensitivity in women with chronic pelvic pain. Obstet Gynecol. 2013;122(5):1047-1055. doi:10.1097/AOG.0b013e3182a7e1f5

77. Baliki MN, Apkarian AV. Nociception, pain, negative moods, and behavior selection. Neuron. 2015;87(3):474-491. doi:10.1016/j. neuron.2015.06.005

78. Hooten WM. Chronic pain and mental health disorders. Mayo Clin Proc. 2016;91(7):955-970. doi:10.1016/j.mayocp.2016.04.029

79. Miller-Matero LR, Saulino C, Clark S, Bugenski M, Eshelman A, Eisenstein D. When treating the pain is not enough: a multidisciplinary approach for chronic pelvic pain. Arch Womens Ment Health. 2016;19(2):349-354. doi:10.1007/s00737-015-0537-9

80. Benson C, Mifflin K, Kerr B, Jesudasan SJB, Dursun S, Baker G. Biogenic amines and the amino acids GABA and glutamate: relationships with pain and depression. In: Finn DP, Leonard BE, Karger AG, editors. Modern Trends in Pharmacopsychiatry; 2015:67-79. Available from https://www.karger.com/Article/FullText/435933.

81. Clark JR, Nijs J, Yeowell G, Holmes P, Goodwin PC. Trait sensitivity, anxiety, and personality are predictive of central sensitization symptoms in patients with chronic low back pain. Pain Pract. 2019;19(8):800-810. doi:10.1111/papr.12809 
82. Borges NC, De Deus JM, Guimarães RA, et al. The incidence of chronic pain following Cesarean section and associated risk factors: a cohort of women followed up for three months. PLoS One. 2020;15(9):e0238634. doi:10.1371/journal.pone.0238634

83. Bryant C, Cockburn R, Plante A-F, Chia A. The psychological profile of women presenting to a multidisciplinary clinic for chronic pelvic pain: high levels of psychological dysfunction and implications for practice. J Pain Res. 2016;9:1049-1056. doi:10.2147/JPR.S115065

84. Brünahl C, Dybowski C, Albrecht R, et al. Mental disorders in patients with chronic pelvic pain syndrome (CPPS). J Psychosom Res. 2017;98:19-26. doi:10.1016/j.jpsychores.2017.04.011

85. Siqueira-Campos VM, Da Luz RA, de Deus JM, Zangiacomi martinez E, Conde DM. Anxiety and depression in women with and without chronic pelvic pain: prevalence and associated factors. J Pain Res. 2019;12:1223-1233. doi:10.2147/JPR.S195317

86. Krantz TE, Andrews N, Petersen TR, et al. Adverse childhood experiences among gynecology patients with chronic pelvic pain. Obstet Gynecol. 2019;134(5):1087-1095. doi:10.1097/AOG.0000000000003533

87. Poli-Neto OB, Tawasha KAS, Romão APMS, et al. History of childhood maltreatment and symptoms of anxiety and depression in women with chronic pelvic pain. J Psychosom Obstet Gynecol. 2018;39(2):83-89. doi:10.1080/0167482X.2017.1306515

88. Siedentopf F, Weijenborg P, Engman M, et al. ISPOG European Consensus Statement - chronic pelvic pain in women (short version). $J$ Psychosom Obstet Gynecol. 2015;36(4):161-170. doi:10.3109/0167482X.2015.1103732

89. Allaire C, Williams C, Bodmer-Roy S, et al. Chronic pelvic pain in an interdisciplinary setting: 1-year prospective cohort. Am J Obstet Gynecol. 2018;218(1):114.e1-114.e12. doi:10.1016/j.ajog.2017.10.002

90. Nunes-Reis AR, Da Luz RA, de Deus JM, Martinez EZ, Conde DM. Association of religiosity with mental health and quality of life in women with chronic pelvic pain. Int J Psychiatry Med. 2020;55(6):408-420. doi:10.1177/0091217420906979

91. Da Luz RA, de Deus JM, Conde DM. Quality of life and associated factors in Brazilian women with chronic pelvic pain. $J$ Pain Res. 2018;11:1367-1374. doi:10.2147/JPR.S168402

92. Royal College of Obstetricians and Gynaecologists. RCOG green-top guideline No. 41: the initial management of chronic pelvic pain. 2nd ed; 2012 [cited 2021]. Available from: https://www.rcog.org.uk/en/guidelines-research-services/guidelines/gtg41/. Accessed February 8, 2022.

93. European Association of Urology. EAU guidelines on chronic pelvic pain. Netherlands; 2021. Available from: https:/uroweb.org/guidelines/ compilations-of-all-guidelines/. Accessed February 8, 2022.

94. Spitzer RL, Kroenke K, Williams JBW, Löwe B. A brief measure for assessing generalized anxiety disorder. Arch Intern Med. 2006;166 (10):1092. doi:10.1001/archinte.166.10.1092

95. Kroenke K, Spitzer RL, Williams JBW. The PHQ-9: validity of a brief depression severity measure. J Gen Intern Med. 2001;16(9):606-613. doi:10.1046/j.1525-1497.2001.016009606.x

96. Zigmond AS, Snaith RP. The hospital anxiety and depression scale. Acta Psychiatr Scand. 1983;67(6):361-370. doi:10.1111/j.1600-0447.1983. tb09716.x

97. Sullivan MJL, Bishop SR, Pivik J. The pain catastrophizing scale: development and validation. Psychol Assess. 1995;7(4):524-532. doi:10.1037/1040-3590.7.4.524

98. Wijma AJ, van Wilgen CP, Meeus M, Nijs J. Clinical biopsychosocial physiotherapy assessment of patients with chronic pain: the first step in pain neuroscience education. Physiother Theory Pract. 2016;32(5):368-384. doi:10.1080/09593985.2016.1194651

99. Weijenborg P, Kuile MM, Gopie JP, Spinhoven P. Predictors of outcome in a cohort of women with chronic pelvic pain - A follow-up study. Eur J Pain. 2009;13(7):769-775. doi:10.1016/j.ejpain.2008.09.002

100. Taylor HS, Kotlyar AM, Flores VA. Endometriosis is a chronic systemic disease: clinical challenges and novel innovations. Lancet. 2021;397 (10276):839-852. doi:10.1016/S0140-6736(21)00389-5

101. Zhang P, Sun Y, Zhang C, et al. Cesarean scar endometriosis: presentation of 198 cases and literature review. BMC Womens Health. 2019;19 (1):14. doi:10.1186/s12905-019-0711-8

102. Jarrell J, Giamberardino MA, Robert M, Nasr-Esfahani M. Bedside testing for chronic pelvic pain: discriminating visceral from somatic pain. Pain Res Treat. 2011;2011:1-6. doi:10.1155/2011/692102

103. Shafrir AL, Martel E, Missmer SA, et al. Pelvic floor, abdominal and uterine tenderness in relation to pressure pain sensitivity among women with endometriosis and chronic pelvic pain. Eur J Obstet Gynecol Reprod Biol. 2021;264:247-253. doi:10.1016/j.ejogrb.2021.07.029

104. Nasr-Esfahani M, Jarrell J. Cotton-tipped applicator test: validity and reliability in chronic pelvic pain. Am J Obstet Gynecol. 2013;208(1):52. e1-52.e5. doi:10.1016/j.ajog.2012.11.005

105. Shy ME, Frohman EM, So YT, et al. Quantitative sensory testing: report of the therapeutics and technology assessment subcommittee of the American Academy of Neurology. Neurology. 2003;60(6):898-904. doi:10.1212/01.WNL.0000058546.16985.11

106. Tirlapur SA, Daniels JP, Khan KS. Chronic pelvic pain: how does noninvasive imaging compare with diagnostic laparoscopy? Curr Opin Obstet Gynecol. 2015;27(6):445-448. doi:10.1097/GCO.0000000000000222

107. Guerriero S, Condous G, van den Bosch T, et al. Systematic approach to sonographic evaluation of the pelvis in women with suspected endometriosis, including terms, definitions and measurements: a consensus opinion from the International Deep Endometriosis Analysis (IDEA) group. Ultrasound Obstet Gynecol. 2016;48(3):318-332. doi:10.1002/uog.15955

108. National Guideline Alliance (Great Britain), National Institute for Health and Care Excellence (Great Britain), Royal College of Obstetricians and Gynaecologists (Great Britain). Endometriosis: diagnosis and management; 2017. Available from: http://www.ncbi.nlm.nih.gov/books/ NBK453273/. Accessed February 8, 2022.

109. Wolf AMD, Fontham ETH, Church TR, et al. Colorectal cancer screening for average-risk adults: 2018 guideline update from the American Cancer Society: ACS colorectal cancer screening guideline. CA Cancer J Clin. 2018;68(4):250-281. doi:10.3322/caac.21457

110. Swank D, Swank-Bordewijk S, Hop W, et al. Laparoscopic adhesiolysis in patients with chronic abdominal pain: a blinded randomised controlled multi-centre trial. Lancet. 2003;361(9365):1247-1251. doi:10.1016/S0140-6736(03)12979-0

111. Molegraaf MJ, Torensma B, Lange CP, Lange JF, Jeekel J, Swank DJ. Twelve-year outcomes of laparoscopic adhesiolysis in patients with chronic abdominal pain: a randomized clinical trial. Surgery. 2017;161(2):415-421. doi:10.1016/j.surg.2016.08.014

112. Chelimsky G, Simpson P, McCabe N, Zhang L, Chelimsky T. collaborative Debra Erickson Dr., Kathleen Pajer Dr., Julian Thayer Dr., Ursula Wesselmann Dr., Phyllis Zee Dr. and Denniz Zolnoun Dr. Autonomic testing in women with chronic pelvic pain. J Urol. 2016;196(2):429-434. doi:10.1016/j.juro.2016.03.142 
113. Donnez J, Dolmans M-M. Endometriosis and medical therapy: from progestogens to progesterone resistance to GnRH antagonists: a review. $J$ Clin Med. 2021;10(5):1085. doi:10.3390/jcm10051085

114. Lumley MA, Schubiner H. Psychological therapy for centralized pain: an integrative assessment and treatment model. Psychosom Med. 2019;81 (2):114-124. doi:10.1097/PSY.0000000000000654

115. Louw A, Zimney K, O'Hotto C, Hilton S. The clinical application of teaching people about pain. Physiother Theory Pract. 2016;32(5):385-395. doi:10.1080/09593985.2016.1194652

116. Cherkin DC, Sherman KJ, Balderson BH, et al. Effect of mindfulness-based stress reduction vs cognitive behavioral therapy or usual care on back pain and functional limitations in adults with chronic low back pain: a randomized clinical trial. JAMA. 2016;315(12):1240. doi:10.1001/ jama.2016.2323

117. Turner JA, Anderson ML, Balderson BH, Cook AJ, Sherman KJ, Cherkin DC. Mindfulness-based stress reduction and cognitive behavioral therapy for chronic low back pain: similar effects on mindfulness, catastrophizing, self-efficacy, and acceptance in a randomized controlled trial. Pain. 2016;157(11):2434-2444. doi:10.1097/j.pain.0000000000000635

118. Konkolÿ Thege B, Petroll C, Rivas C, Scholtens S. The effectiveness of family constellation therapy in improving mental health: a systematic review. Fam Process. 2021;60(2):409-423. doi:10.1111/famp.12636

119. Hunter CW, Yang A. Dorsal root ganglion stimulation for chronic pelvic pain: a case series and technical report on a novel lead configuration. Neuromodulation. 2019;22(1):87-95. doi:10.1111/ner.12801

120. Schu S, Gulve A, ElDabe S, et al. Spinal cord stimulation of the dorsal root ganglion for groin pain-A retrospective review. Pain Pract. $2015 ; 15$ (4):293-299. doi:10.1111/papr.12194

121. Levine AB, Parrent AG, MacDougall KW. Stimulation of the spinal cord and dorsal nerve roots for chronic groin, pelvic, and abdominal pain. Pain Physician. 2016;19(6):405-412.

122. Bridger C, Prabhala T, Dawson R, et al. Neuromodulation for chronic pelvic pain: a single-institution experience with a collaborative team. Neurosurgery. 2021;88(4):819-827. doi:10.1093/neuros/nyaa537

123. Deer TR, Levy RM, Kramer J, et al. Dorsal root ganglion stimulation yielded higher treatment success rate for complex regional pain syndrome and causalgia at 3 and 12 months: a randomized comparative trial. Pain. 2017;158(4):669-681. doi:10.1097/j.pain.0000000000000814

124. Nagpal A, Clements N, Duszynski B, Boies B. The effectiveness of dorsal root ganglion neurostimulation for the treatment of chronic pelvic pain and chronic neuropathic pain of the lower extremity: a comprehensive review of the published data. Pain Med. 2021;22(1):49-59. doi:10.1093/pm/pnaa369

125. Fukudo S, Okumura T, Inamori M, et al. Evidence-based clinical practice guidelines for irritable bowel syndrome 2020. $J$ Gastroenterol. 2021;56(3):193-217. doi:10.1007/s00535-020-01746-z

126. Oh-Oka H. Clinical efficacy of 1-year intensive systematic dietary manipulation as complementary and alternative medicine therapies on female patients with interstitial cystitis/bladder pain syndrome. Urology. 2017;106:50-54. doi:10.1016/j.urology.2017.02.053

127. Bull FC, Al-Ansari SS, Biddle S, et al. World Health Organization 2020 guidelines on physical activity and sedentary behaviour. Br J Sports Med. 2020;54(24):1451-1462. doi:10.1136/bjsports-2020-102955

128. Geneen LJ, Moore RA, Clarke C, Martin D, Colvin LA, Smith BH. Physical activity and exercise for chronic pain in adults: an overview of cochrane reviews. Cochrane Database Syst Rev. 2017:CD011279. doi:10.1002/14651858.CD011279.pub3

129. Hansen S, Sverrisdóttir UÁ, Rudnicki M. Impact of exercise on pain perception in women with endometriosis: a systematic review. Acta Obstet Gynecol Scand. 2021;100(9):1595-1601. doi:10.1111/aogs.14169

130. Buggio L, Somigliana E, Barbara G, Frattaruolo MP, Vercellini P. Oral and depot progestin therapy for endometriosis: towards a personalized medicine. Expert Opin Pharmacother. 2017;18(15):1569-1581. doi:10.1080/14656566.2017.1381086

131. Barra F, Scala C, Ferrero S. Current understanding on pharmacokinetics, clinical efficacy and safety of progestins for treating pain associated to endometriosis. Expert Opin Drug Metab Toxicol. 2018;14(4):399-415. doi:10.1080/17425255.2018.1461840

132. Gallagher JS, Missmer SA, Hornstein MD, Laufer MR, Gordon CM, DiVasta AD. Long-term effects of Gonadotropin-Releasing hormone agonists and add-back in adolescent endometriosis. J Pediatr Adolesc Gynecol. 2018;31(4):376-381. doi:10.1016/j.jpag.2018.03.004

133. Brown J, Crawford TJ, Datta S, Prentice A. Oral contraceptives for pain associated with endometriosis. Cochrane Database Syst Rev. 2018;2018(5). doi:10.1002/14651858.CD001019.pub3

134. Macfarlane GJ, Kronisch C, Dean LE, et al. EULAR revised recommendations for the management of fibromyalgia. Ann Rheum Dis. 2017;76 (2):318-328. doi:10.1136/annrheumdis-2016-209724

135. Santos T, Miranda I, Nygaard C, Schreiner L, Castro R, Haddad J. Systematic review of oral therapy for the treatment of symptoms of bladder pain syndrome: the Brazilian guidelines. Rev Bras Ginecol e Obstet. 2018;40(02):096-102. doi:10.1055/s-0037-1609049

136. Weinberg DS, Smalley W, Heidelbaugh JJ, Sultan S. American gastroenterological association institute guideline on the pharmacological management of irritable bowel syndrome. Gastroenterology. 2014;147(5):1146-1148. doi:10.1053/j.gastro.2014.09.001

137. Sator-Katzenschlager SM, Scharbert G, Kress HG, et al. Chronic pelvic pain treated with gabapentin and amitriptyline: a randomized controlled pilot study. Wien Klin Wochenschr. 2005;117(21-22):761-768. doi:10.1007/s00508-005-0464-2

138. Moore RA, Derry S, Aldington D, Cole P, Wiffen PJ. Amitriptyline for neuropathic pain in adults. Cochrane Database Syst Rev. 2015. doi:10.1002/14651858.CD008242.pub2

139. Derry S, Wiffen PJ, Aldington D, Moore RA. Nortriptyline for neuropathic pain in adults. Cochrane Database Syst Rev. 2015. doi:10.1002/ 14651858.CD011209.pub2

140. Hearn L, Derry S, Phillips T, Moore RA, Wiffen PJ. Imipramine for neuropathic pain in adults. Cochrane Database Syst Rev. 2014. doi:10.1002/14651858.CD010769.pub2

141. Hearn L, Moore RA, Derry S, Wiffen PJ, Phillips T. Desipramine for neuropathic pain in adults. Cochrane Database Syst Rev. $2014:$ CD011003. doi:10.1002/14651858.CD011003.pub2

142. Caruso R, Ostuzzi G, Turrini G, et al. Beyond pain: can antidepressants improve depressive symptoms and quality of life in patients with neuropathic pain? A systematic review and meta-analysis. Pain. 2019;160(10):2186-2198. doi:10.1097/j.pain.0000000000001622

143. Lunn MP, Hughes RA, Wiffen PJ. Duloxetine for treating painful neuropathy, chronic pain or fibromyalgia. Cochrane Database Syst Rev. 2014. doi:10.1002/14651858.CD007115.pub3 
144. Valentine L, Deimling T. Opioids and alternatives in female chronic pelvic pain. Semin Reprod Med. 2018;36(02):164-172. doi:10.1055/s-00381676102

145. Fan X-M, Ren Y-F, Fu X, et al. Gabapentin has longer-term efficacy for the treatment of chronic pelvic pain in women: a systematic review and pilot meta-analysis. Pain Ther. 2021;10(2):1673-1689. doi:10.1007/s40122-021-00330-4

146. Derry S, Bell RF, Straube S, Wiffen PJ, Aldington D, Moore RA. Pregabalin for neuropathic pain in adults. Cochrane Database Syst Rev. 2019. doi:10.1002/14651858.CD007076.pub3

147. Mücke M, Phillips T, Radbruch L, Petzke F, Häuser W. Cannabis-based medicines for chronic neuropathic pain in adults. Cochrane Database Syst Rev. 2018;2020(7). doi:10.1002/14651858.CD012182.pub2

148. Chang Y, Zhu M, Vannabouathong C, Mundi R, Chou RS, Bhandari M. Medical cannabis for chronic noncancer pain: a systematic review of health care recommendations. Pain Res Manag. 2021;2021:1-9.

149. Okusanya BO, Asaolu IO, Ehiri JE, Kimaru LJ, Okechukwu A, Rosales C. Medical cannabis for the reduction of opioid dosage in the treatment of non-cancer chronic pain: a systematic review. Syst Rev. 2020;9(1):167. doi:10.1186/s13643-020-01425-3

150. Marcu I, Gee A, Lynn B. Cannabinoids and chronic pelvic pain in women: focus on endometriosis. J Endometr Pelvic Pain Disord. 2021;13 (3):155-165. doi:10.1177/22840265211011277

151. Andres MP, Mendes RFP, Hernandes C, Araújo SEA, Podgaec S. Hormone treatment as first line therapy is safe and relieves pelvic pain in women with bowel endometriosis. Einstein São Paulo. 2019;17(2):eAO4583. doi:10.31744/einstein_journal/2019AO4583

152. Vercellini P, Sergenti G, Buggio L, Frattaruolo MP, Dridi D, Berlanda N. Advances in the medical management of bowel endometriosis. Best Pract Res Clin Obstet Gynaecol. 2021;71:78-99. doi:10.1016/j.bpobgyn.2020.06.004

153. Bafort C, Beebeejaun Y, Tomassetti C, Bosteels J, Duffy JM. Laparoscopic surgery for endometriosis. Cochrane Database Syst Rev. 2020;2020 (10). doi:10.1002/14651858.CD011031.pub3

154. Levesque A, Ploteau S, Michel F, et al. Botulinum toxin infiltrations versus local anaesthetic infiltrations in pelvic floor myofascial pain: multicentre, randomized, double-blind study. Ann Phys Rehabil Med. 2021;64(1):101354. doi:10.1016/j.rehab.2019.12.009

155. Grinberg K, Weissman-Fogel I, Lowenstein L, Abramov L, Granot M. How does myofascial physical therapy attenuate pain in chronic pelvic pain syndrome? Pain Res Manag. 2019;2019:1-11. doi:10.1155/2019/6091257

156. van Reijn-baggen DA, Han-Geurts IJM, Voorham-van der Zalm PJ, et al. Pelvic floor physical therapy for pelvic floor hypertonicity: a systematic review of treatment efficacy. Sex Med Rev. 2021:S2050052121000123. doi:10.1016/j.sxmr.2021.03.002

157. Weaver KR, Melkus GD, Henderson WA. Irritable bowel syndrome. Am J Nurs. 2017;117(6):48-55. doi:10.1097/01. NAJ.0000520253.57459.01

158. Scaciota ACL, Matos D, Rosa MMB, Colovati MES, Bellotto EFBC, Martimbianco ALC. Interventions for the treatment of irritable bowel syndrome: a review of cochrane systematic reviews. Arq Gastroenterol. 2021;58(1):120-126. doi:10.1590/s0004-2803.202100000-20

159. Imamura M, Scott NW, Wallace SA, et al. Interventions for treating people with symptoms of bladder pain syndrome: a network meta-analysis. Cochrane Database Syst Rev. 2020;2020(7). doi:10.1002/14651858.CD013325.pub2

160. Malde S, Palmisani S, Al-Kaisy A, Sahai A. Guideline of guidelines: bladder pain syndrome. BJU Int. 2018;122(5):729-743. doi:10.1111/ bju. 14399

\section{Publish your work in this journal}

The International Journal of Women's Health is an international, peer-reviewed open-access journal publishing original research, reports, editorials, reviews and commentaries on all aspects of women's healthcare including gynecology, obstetrics, and breast cancer. The manuscript management system is completely online and includes a very quick and fair peer-review system, which is all easy to use. Visit http://www. dovepress.com/testimonials.php to read real quotes from published authors.

Submit your manuscript here: https://www.dovepress.com/international-journal-of-womens-health-journal 